\title{
WEAK ISLANDS AND AN ALGEBRAIC SEMANTICS FOR SCOPE TAKING*
}

\section{Anna Szabolcsi and Frans Zwarts ${ }^{1}$}

\author{
Department of Linguistics \\ $U C L A$ \\ ${ }^{1}$ Rijkuniversiteit Groningen
}

\section{INTRODUCTION ${ }^{\dagger}$}

This paper outlines a semantic approach to weak islands, a phenomenon that has traditionally been thought of as purely syntactic. Weak islands are environments that allow some, but not all, wh-phrases to extract:

(1) a. Which man didn't you invite?

b. * How didn't you behave?

(2) a. Which man do you regret that I invited?

b. * How do you regret that I behaved?

We propose that at least in a significant set of the cases the violation is semantic in nature. In agreement with É. Kiss (1992) and de Swart (1992), we informally characterize the role of interveners as follows:

(3) Weak island violations come about when an extracted phrase should take scope over some intervener but is unable to.

${ }^{*}$ Parts of this paper appeared in Szabolcsi $(1992 \mathrm{~b})$. We had extremely helpful discussions with many colleagues, at UCLA and elsewhere, over the past two years. We wish to thank them all, especially F. Beghelli, D. Ben-Shalom, C. Dobrovie-Sorin, E. Engdahl, I. Heim, J. Higginbotham, J. Hoeksema, M. Krifka, L. Moritz, D. Oehrle, B. Partee, D. Pesetsky, B. Schein, D. Sportiche, E. Stabler, T. Stowell, and H. de Swart, and two anonymous NALS reviewers of an earlier version of this paper entitled 'Weak Islands and Algebraic Semantics.'

${ }^{\dagger}$ This paper is reprinted from Natural Language Semantics 1 (1993, pp. 235-284). No attempt is made here to correct whatever global shortcomings it may have. However, a handful of footnotes are added by the alphabetically first author to enhance clarity. The new footnotes do not interfere with the original numbering; they are indicated by the traditional sequence of footnote symbols. 
(4) Harmless interveners are harmless only in that they can give rise to at least one reading of the sentence that presents no scopal conflict of the above sort: they can "get out of the way."

This paper's principal contribution consists in an algebraic semantic explication of scope taking. A scopal element SE as we will understand it is an item that can participate in scope ambiguities; of the cases in which a wh-phrase takes scope over some SE, we will restrict our attention to those which can be represented by letting the $w h$-phrase bind a variable within the scope of SE. The variable $x$ can be of any logical type: ${ }^{1}$

(5) $\mathrm{WH} x\left[\ldots \mathrm{SE}\left({ }_{\alpha} \ldots x \ldots\right)\right]$

The specific semantics of SE does not tend to receive much attention in this context. But (5) is meaningful only if $\mathrm{SE}$ is given an appropriate argument. For instance, if $\mathrm{SE}$ is negation, the expression $\alpha$ must denote in a domain for which complements are defined. Whether $\alpha$ does so depends, to a great extent, on the semantics of $\mathrm{WH} x$. This is the connection that we will explore.

(6) Scope and operations

Each scopal element SE is associated with certain operations (e.g., not with complements). For a $w h$-phrase to take scope over some SE means that the operations associated with SE need to be performed in the whphrase's denotation domain. If the wh-phrase denotes in a domain for which the requisite operation is not defined, it cannot scope over SE.

This approach requires at least a partial semantic analysis of extractees as well as interveners. For instance, to account for (1), it needs to be shown that which man ranges over a domain for which complements are defined, but how does not; further aspects of their meanings may remain obscure because they are not relevant. Or, to account for (2), at least one operation that is not defined for the how-domain needs to be identified in the factive context; further aspects of its meaning are not relevant. We will indeed propose such analyses for a few extractees and interveners, leaving others for further research.

Intuitively, we are assimilating the scopal failure in weak islands to the application of a numeral to a mass noun, which is unacceptable because counting cannot be defined for the mass domain:

$(7) * \operatorname{six}$ mists

\footnotetext{
${ }^{1}$ If $F$ and $G$ are (polymorphic) functions, we say that $F$ can participate in scope ambiguities if for some $G, F \circ G$ and $G \circ F$ are not logically equivalent; see Keenan and Timberlake (1988). Generalized quantifiers, operators like negation, intensional verbs, etc. all fall under this definition. As regards scoping, the reference to binding a variable within the scope of SE merely serves the purpose of exposition and is not meant to commit us to any particular kind of representation.
} 
This is to be distinguished from another type of scopal failure which is tied to particular syntactic configurations, for instance:

(8) a. Every man read few books.

* 'There are few books such that every man read them'

b. Few books were read by every man.

'There are few books such that every man read them'

c. Few books did every man read.

'There are few books such that every man read them'

As Liu (1990) observes, part of the descriptive generalization is in semantic terms: downward monotonic quantifiers in object position do not take scope over the subject. But unlike the weak island cases, the reason here cannot be that the ensuing meaning would be incoherent, as it is in fact available in slightly different structures.

The present proposal builds on the results in Szabolcsi and Zwarts (1990, 1991), but also differs from it in fundamental ways. The earlier proposal was a rather direct semantic reinterpretation of the data underlying Rizzi's (1990) and Cinque's (1990) Relativized Minimality, and made the following main claims:

(9) Island-escapers are individuals

Wh-phrases that are sensitive to weak islands are the ones that range over partially ordered domains, rather than discrete individuals.

(10) Weak islands and monotonicity

Weak islands are environments in which the interveners between the wh-phrase and its trace cannot be composed into an upward monotonic function. The reason is that only upward monotonic functions preserve partial ordering.

It will be argued below that (9) is essentially correct, but interveners are to be characterized in terms of scope, rather than monotonicity properties, thus (10) is to be abandoned.

The discussion will be organized as follows. Section 2 reviews the core weak islands data, and outlines the accounts in Rizzi (1990) and Cinque (1990) on the one hand and in Szabolcsi and Zwarts $(1990,1991)$ on the other. Section 3 summarizes the monotonicity account and points out its problematic aspects, including some shared by Relativized Minimality. Section 4 proposes an alternative account in terms of scope. The present paper focuses on why non-individual wh-phrases do not take wide scope, cf. (3), with only a few remarks concerning (4). Section 5.1 outlines the connection between scope and algebraic operations, cf. (6). Section 5.2 presents detailed empirical justification for the individual vs ordered distinction, cf. (8), and Section 5.3 discusses 
its implementation in algebraic terms, and Section 5.4 predicative interveners. Section 6.1 introduces a novel set of data involving arguments of non-iterable predicates that support this account over ones in terms of discourse or thematic roles; Section 6.2 establishes a connection between event structure and whether the predicate denotes an ordered or an unordered set. Some formal details of scopal intervention are also spelled out. Section 7 is a brief conclusion.

\section{WEAK ISLANDS: SOME FACTS AND TWO ACCOUNTS}

\subsection{Weak island facts and relativized minimality}

Islands for extraction come in two varieties. Strong islands are absolute: they do not allow any $w h$-phrase to escape. Cinque (1990) argues that subject, complex NP, and adjunct islands belong here: the NP gap they may contain is an empty resumptive pronoun, not a trace. Weak islands, on the other hand, are selective: typically, phrases like which man can extract, but phrases like why, how, and how many pounds cannot. The cross-linguistically best known weak islands are infinitival/subjunctive/modal whether-clauses:

a. Which $\operatorname{man}_{\mathrm{i}}$ are you wondering [whether to invite $-_{\mathrm{i}}$ ] ?

b. ${ }^{*}$ How $_{\mathrm{i}}$ are you wondering [whether to behave $-\mathrm{i}$ ] ?

c. Welke $\operatorname{man}_{\mathrm{i}}$ heb jij je afgevraagd [of je $-\mathrm{i}$ moet which man have you self wonder if you must uitnodigen]?

invite

'Which man did you wonder whether you should invite?'

d. ${ }^{*} \mathrm{Hoe}_{\mathrm{i}}$ heb jij je afgevraagd [of je je-i moet how have you self wondered if you self must gedragen]?

behave

'How did you wonder whether you should behave?'

Extraction from embedded constituent questions is degraded or unacceptable for many speakers of English. In other languages these may either be strong islands (Dutch) or genuine weak islands (Hungarian): ${ }^{2}$

(12) ?/* Which $\operatorname{man}_{\mathrm{i}}$ are you wondering [who saw - i] ?

\footnotetext{
${ }^{2}$ Comorovski (1989) states, albeit without providing an explanation, that complements of wonder-type verbs constitute absolute islands. Her claim is at variance with both standard literature and our own judgments.
} 
(13) * Welke $\operatorname{man}_{\mathrm{i}}$ heb jij je afgevraagd [wie - $\mathrm{i}$ gezien heeft]? which man have you self wondered who seen has 'Which man did you wonder who saw?'

(14) Melyik embert $t_{i}$ találgattad, [hogy ki látta -i ] which man-Acc guessed-you that who saw 'Which man were you wondering who saw?'

Although the variation in (12) through (14) is not well-understood, we will follow standard practice both in assuming that the strong islandhood of certain wh-complements is syntactic in nature and in restricting our attention to examples that qualify as weak islands in the given dialect or language.

Drawing from work by H. Obenauer and J. Ross, Rizzi (1990) and Cinque (1990) observe that the same kind of selectivity is exhibited by many further environments: the presence of beaucoup 'a lot' in French, negation or negative quantifiers, only-phrases, adversative and factive predicates, and extraposition all create weak islands:
a. Quel livre as-tu beaucoup consulté - ?
what book have-you a lot consulted
'What book did you consult a lot?'
b. * Combien as-tu beaucoup consulté - de livres? how-many have-you a lot consulted of books

(16) a. Which man didn't you/did no one think that I invited -?

b. * How didn't you/did no one think that I behaved - ?

a. Which man did only John think that I invited - ?

b. * How did only John think that I behaved - ?

a. Which man did you deny/regret that I invited - ?

b. * How did you deny/regret that I behaved -?

a. Which man was it a scandal that I invited - ?

b. * How was it a scandal that I behaved -?

Compare the following good how-extraction:

(20) How did everyone/two men think that I behaved -?

They propose the following uniform explanation for the contrasts in (10) through (20): 
(21) Referential wh-phrases can be long-distance linked to their traces via referential indices; non-referential wh-phrases need to be linked to their traces via an (antecedent-) government chain.

(22) The government chain between a non-referential $w h$-phrase and its trace is broken

(i) by certain interveners, or

(ii) if the clause from which we extract is not sister of a theta-marking $[+\mathrm{V}]$ head.

(23) Referential wh-phrases are those that both bear a thematic role like Agent, Patient, etc. and are Discourse-linked; non-referential wh-phrases are those that bear a role like Reason, Manner, Measure, etc. or are not D-linked.

The majority of the weak island effects is attributed to (22i). What interveners break the government chain between the how-type phrase and its trace? Rizzi's answer is in terms of syntactic positions. Developing the theory of Relativized Minimality, he argues that since the extracted wh-phrase is in an A-bar specifier position, all and only intervening $A$-bar specifiers count as relevant interveners. Rizzi analyzes whether, who, beaucoup, not, no one, only John and deny as A-bar specifiers, at S-structure or at LF. In contrast, he points out that everyone or two men acquire their scope by adjunction according to May (1985), so they are predicted not to block non-referential extraction. Cinque adds that factive and extraposition islands are due to (22ii).

As regards referentiality, Rizzi draws the crucial line between those phrases that refer to participants in the event and those that do not; the latter are claimed never to be able to escape from weak islands. Drawing from Pesetsky's (1987), Comorovski's (1989), and Kroch's (1989) work, Cinque adds that even event participants have to be D-linked, i.e., "refer to specific members of a preestablished set," to be referential. Phrases differ in their ability to admit of a D-linked interpretation, so a scale is predicted:

(24) a. Which man do you regret that I saw -?

b. ? Who do you regret that I saw - ?

c. ?? What do you regret that I saw -?

d. ?? How many books do you regret that I saw - ?

e. * How much pain do you regret that I saw - ?

f. * Who the hell do you regret that I saw -? 


\subsection{Recasting relativized minimality in semantic terms}

Szabolcsi and Zwarts $(1990,1991)$ and Szabolcsi (1991) - henceforth Sz and $\mathrm{Z}$ - accept the above empirical generalizations and propose to reinterpret them in semantic terms. The main claims are as follows.

The distinction between good extractees and bad extractees can be characterized in denotational terms. Good extractees range over individual domains, bad ones over domains whose elements exhibit a partial ordering (a reflexive, transitive and antisymmetric relation; paradigmatically: inclusion). On their primary use, properties, amounts, manners, etc. belong to partially ordered domains. The term 'individual' is used to refer both to inherently discrete entities like John or Mary and to contextually individuated properties, amounts, etc.; individuation means that we expressly choose to ignore their overlaps.

The characterization of weak islands can be given in terms of the monotonicity properties of the items intervening between the extractee and its trace. Downward monotonic and nonmonotonic interveners block the extraction of non-individuals; upward monotonic ones are harmless. The connection lies in the fact that only upward monotonic environments preserve partial ordering. Since individuals are not ordered, they are not interested, so to speak, in whether ordering is preserved: they must be insensitive to weak islands. Non-individuals are ordered, so they can naturally require that the structure of their domain be preserved between the extraction site and the landing site.

These claims can be implemented in a grammar whether or not it has movement and traces. For instance, they can be expressed as a condition on wh-trace relations. Or, they can be implemented in a categorial grammar that handles extraction using function composition: ${ }^{3}$

$$
\begin{array}{ll}
\text { How much milk } & \operatorname{did}\left({ }^{*} \text { n't }\right) \text { you drink } \\
/(\mathrm{S} / \mathrm{NP})_{\text {MON }} & (\mathrm{S} / \mathrm{NP})_{\text {MON }} \\
\mathrm{S} &
\end{array}
$$

Assume that how much milk is marked to apply to an expression of category $\mathrm{S} / \mathrm{NP}$ only if it denotes an upward monotonic function. This assumption is methodologically analogous to (in fact, is inspired by) Zwarts's (1986) claim that negative polarity items must be arguments of downward monotonic functions. Categorial grammar assembles form and meaning simultaneously. Since monotonicity properties are inherited under composition, did you drink will be

\footnotetext{
${ }^{3}$ If the extracted phrase is an adjunct, a functor looking for it is created by lifting the category to be modified by the adjunct.
} 
upward monotonic, whereas didn't you drink will inherit downward monotonicity from $n t^{\prime} .^{4}$

In the following sections we discuss the empirical motivation for the monotonicity claims in some detail, and then go on to point out its problematic aspects. The individual vs. ordered distinction will be essentially maintained in the revised proposal; its empirical as well as algebraic elaboration is relegated to Sections 5.2 and 5.3.

\section{WEAK ISLANDS AND MONOTONICITY}

\subsection{Summary of claims}

Szabolcsi and Zwarts observe that the environments Rizzi and Cinque characterize as weak islands share some simple monotonicity properties: they are all either downward monotonic or nonmonotonic.

a. A function $f$ is upward monotonic iff for every $A, B$ in its domain, if $A \subseteq B$, then $f(A) \subseteq f(B)$.

b. A function $f$ is downward monotonic iff for every $A, B$ in its domain, if $A \subseteq B$, then $f(A) \supseteq f(B)$.

c. A function $f$ is nonmonotonic iff neither (a) nor (b).

Let us briefly review how the material in Section 2.1 fits these notions. Not, no one, and deny are clearly downward monotonic; by the same token, we predict that few men and at most five men also create weak islands. Whphrases, factives like regret, only-phrases, and beaucoup 'a lot' are analyzed as nonmonotonic. Since some of these items are focus-sensitive, we try to keep the focus structure of the examples constant: ${ }^{5}$

a. [I know the answer to the question] who/whether he exercises $\nLeftarrow \& \not \rightarrow$

${ }^{4}$ The combinatory grammars in Steedman (1987) and Szabolcsi (1992a) have nothing to say about island constraints. To remedy this, Hepple (1990) introduces boundary modalities and what may be called a calculus of opacity. But he makes no empirical claims concerning what domains will be opaque for what relations, and why. The present paper tries to argue on empirical grounds that some of the island constraints are semantic in nature. It remains to be seen whether boundary modalities can encode the semantic generalizations or become, at least in this case, superfluous.

${ }^{5}$ Some comments on (28) and (30). (28) is clearly invalid in the $\mathrm{b} \rightarrow$ a direction. The $\mathrm{a} \rightarrow \mathrm{b}$ direction may be tempting, but (b) has a more specific presupposition than (a), whence it cannot be entailed by (a). Some factives like know are upward monotonic if taken extensionally. See Ladusaw (1980) on both points. In (30), the non-monotonic analysis of beaucoup, a lot, etc. is inspired by Westerståhl (1985), who proposes four interpretations for many, two of which are non-monotonic due to context-dependence. Suppose John does nothing but push-ups for exercise. What he does may count as a lot of push-ups but not as a lot of exercise, if the norms associated with the two are different. De Swart (1992) points 
b. [I know the answer to the question] who/whether he does push-ups

a. John regrets that I exercise $\nLeftarrow \& \not \rightarrow$

b. John regrets that I do push-ups

(29) a. Only John exercises $\not \& \not \rightarrow$

b. Only John does push-ups
a. John exercises a lot $\nLeftarrow \& \not \rightarrow$
b. John does push-ups a lot

By the same token, we predict that exactly five men and often, etc. also create weak islands. On the other hand, items like think, John, everyone, two men, etc., which do not create weak islands, are upward monotonic. (It is difficult to find a good sample of extraposition islands that are not also factive islands; no proposal is made for them in Szabolcsi and Zwarts.)

This descriptive characterization avoids some analytical problems that arise on Rizzi's and Cinque's analyses. They include the movement of deny, a head, into an A-bar specifier position at LF and the assumption that the complement of regret is not a sister to the verb. These have an alternative solution within Relativized Minimality, however: the adoption of Progovac's (1988) and Melvold's (1991) proposals to place empty operators in the [SPEC, CP] of the complements of deny and regret, which then serve as standard interveners. More important perhaps is the problem posed by the cross-linguistic variation in the syntax of negation. Recent work has attributed the variation to the fact that the negative particle may be a head, a specifier, or an adjunct. This would suggest that the island-creating effect of negation varies accordingly, but it does not: we are not aware of any language in which negation does not create a weak island. Rizzi (1992) proposes to solve this problem by assuming an empty Abar specifier when NEG is a head, and vice versa. But this solution makes the original claim almost vacuous; it seems more natural to us to trace back the cross-linguistically uniform effect to the uniform semantics of negation.

The most important question is why downward monotonic and nonmonotonic environments constitute weak islands. The definitions in (26) make it clear that upward monotonicity means simply that the function preserves partial ordering; downward monotonic functions reverse it and nonmonotonic ones obliterate it. Now recall that in the previous section we claimed that islandsensitive phrases are characterized by the fact that they range over a partially ordered domain. It seems entirely natural for such a phrase to require that

out that on this view seldom would be nonmonotonic, too, which contradicts its ability to license negative polarity items. But this may be more of a problem for NPI-theories than for us: only John and regret are also NPI-licensers and nonmonotonic. 
order be preserved by the path connecting it to its extraction site. On the other hand, wh-phrases that range over individuals do not have a partial order in their domain. Hence they cannot possibly be sensitive to the preservation of order and must be immune to weak islands-which they are.

\subsection{Problems}

The problems with the above proposal come in two varieties: descriptive and conceptual.

(31) There are downward monotonic and nonmonotonic interveners that for many speakers do not create weak islands.

(32) There are upward monotonic interveners which do create weak islands.

(33) Two downward monotonic items in the path do not (regularly) cancel out.

(34) The explanation of why downward monotonic and nonmonotonic paths are islands is not as strong as it should be.

Let us consider these in turn.

First, Szabolcsi and Zwarts predict that all non-upward monotonic interveners are equally bad. But many speakers report a contrast between (35a) and $(35 \mathrm{~b}, \mathrm{c})$ :
a. * How did few people think that you behaved?
MON $\downarrow$
b. How did exactly five people think that you behaved? -MON
c. How did at most five people think that you behaved? MON $\downarrow$

Second, Szabolcsi and Zwarts predict that all upward monotonic interveners are harmless. ${ }^{6}$ De Swart (1992) examines combien-extraction and Dutch wat voor-split, and observes that clearly upward iterative adverbs like twee keer 'twice' create as bad islands as downward monotonic ones. She also reanalyzes beaucoup, veel 'a lot' as upward monotonic; this may be a matter of debate, cf. note 5 , but 'twice' alone is sufficient to establish her case:
a. Wat voor boeken heb je twee keer gelezen? what for books have you twice read 'What (sort of) books have you read twice?'
b. * Wat heb je twee keer voor boeken gelezen? what have you twice for books read

\footnotetext{
${ }^{6}$ Szabolcsi and Zwarts (1991) has a chapter on 'gradience,' but its data are not built into the theory. We will return to this below. See also Philip and de Villiers (1992).
} 
Similarly, Hegarty (1992) argues that the class of matrix predicates that constitute weak islands is not that of factives but, rather, Cattell's (1978) response stance and non-stance verbs, in distinction to volunteered stance ones. Dukes (1992) notes that several of the new island creators in (37)-(38) are upward monotonic:

(37) Response stance: deny, accept, agree, confirm, verify, admit

(38) Non-stance: know, regret, remember, surprise, realize, notice

(39) Volunteered stance: think, believe, suspect, allege, assume, claim

Third, the most natural implementation of Szabolcsi and Zwarts's proposal, as was mentioned in Section 2.2, is to assume that interveners between the whphrase and its trace are composed into one big function, each contributing its own semantic properties to the result. This predicts that examples containing two downward monotonic interveners are grammatical, since the composition of two downward monotonic functions is upward monotonic. Now, there is at least one case, (40c), where this is borne out:
a. * John is our hero, as you deny.
b. * John is our hero, as no one knows.
c. John is our hero, as no one denies.
d. John is our hero, as you know.

Many of our informants report that they sense an improvement with whextraction, too, but it does not prove significant under closer scrutiny:
a. * How did he deny that you behaved?
b. ?? How did no one deny that you behaved?

In view of this last observation one may choose to abandon the path-minded formulation of the hypothesis, and use monotonicity properties to characterize bad interveners. This, however, makes the explanation somewhat stipulative.

Fourth, Szabolcsi and Zwarts point out that the link between the partially ordered nature of sensitive extractees and the non-upward monotonic nature of weak islands is not as strong as it should be. The theory explains clearly why individuals cannot be sensitive to weak islands, and why non-individuals can be. But it does not explain why they are sensitive, i.e., exactly what goes wrong when partial ordering is not preserved.

Individually, these descriptive and conceptual problems are not devastating; they might be seen as calling for further research. Together, however, they indicate that the explanation is on the wrong track. 
To see an important source of the problems, let us recall a crucial assumption of the Relativized Minimality theory (RM). The theory of LF that RM relies on is that of May (1985). According to this theory, structure (usually) does not disambiguate scope. (42), for instance, is assigned a single structure in which how is higher than everyone, but they govern each other, whence they can be interpreted in either scope order or even independently. The adoption of this theory for the purposes of RM results in the assumption that it does not matter which reading of the sentence we are considering; all we have to know is that everyone is in an adjoined position, whence its intervention between how and its trace must be harmless. (43) is also assigned a single structure, but no one occupies an A-bar specifier position in it, whence it must block how-extraction.

(42) How did everyone behave?

(43) * How did no one behave?

Szabolcsi and Zwarts followed RM in this respect. The claim that certain interveners hurt because, being A-bar specifiers, they break a government chain, was replaced by the claim that they hurt because non-upward monotonic paths do not preserve partial order-but the assumption that upward monotonic interveners qua interveners are harmless became part and parcel of the theory.

Results by É. Kiss (1992) and de Swart (1992) indicate that this assumption is wrong. In addition to pointing out the island creating effect of iterative adverbs (cf. 36) de Swart notes that sentences like (44) are potentially ambiguous, and they are ungrammatical on the narrow scope universal reading.

(44) Combien ont-ils tous lu de livres? how many have-they all read of books 'For each of them, tell me what number of books he read'

* 'For what number, they all read that number of books'

Similarly, É. Kiss points out that (42) has only readings (a) and (b), but not the narrow scope universal reading $(c)$ :

(42) How did everyone behave?
a. 'For every person, how did he behave?'
b. 'What was the uniform behavior exhibited by everyone?'
c. * 'For what manner, everyone behaved in that manner?'

In retrospect, the conclusion that upward quantifiers are not harmless when they expressly take narrow scope had been anticipated in Szabolcsi $(1983,1986)$ and in Szabolcsi and Zwarts's (1991) chapter on gradience in the strength of 
islands. Because of the conflict with RM, however, the pertinent data were excluded from the core set on which the Szabolcsi and Zwarts account was based.

We leave the question open whether Relativized Minimality can be restated to cope with these data. The restatement would have to involve a modified concept of LF and/or a modified definition of interveners. See Dobrovie-Sorin (1992) and Beghelli (1993) for work in this direction.

\section{WEAK ISLANDS AND SCOPE}

In what follows we will assume that weak islands are a scope phenomenon. That is, we adopt the following informal version of É. Kiss's (1992) and de Swart's (1992) proposals as a point of departure:

(45) The weak island effect comes about when the wh-phrase should take wide scope over some operator but it is unable to.

(46) Harmless interveners are only harmless in that they can give rise to at least one reading of the sentence that presents no scopal conflict of the above sort: they can "get out of the way."

É. Kiss and de Swart present their proposals in terms of filters:

(47) "Specificity Filter: If Opi is an operator which has scope over Opj and binds a variable in the scope of $\mathrm{Opj}$, then Opi must be specific" (in the sense of Enç 1991) (É. Kiss 1992).

(48) "A quantifier Q1 can only separate a quantifier Q2 from its restrictive clause if Q1 has wide scope over Q2 (or is scopally independently from Q2)" (de Swart 1992, p. 402).

In developing a formal semantic explanation, at least two questions need to be asked:

(49) Why are certain wh-phrases restricted in their scope-taking abilities?

(50) What interveners are able to "get out of the way," and how?

In the following sections we will focus on (49). An answer to (50) is to be developed in Szabolcsi (1996) and Doetjes and Honcoop (1996, Section 5.3), within the context of how scope behavior is determined by the meanings of the specific quantifiers. Before turning to (49), however, we provide a brief overview of some results in the literature that pertain to (50), and indicate their relation to the monotonicity hypotheses in Szabolcsi and Zwarts. 
An intervener ${ }^{7}$ is harmless iff (i) it is scopeless, or (ii) it can take wide scope over the $w h$-phrase (family-of-questions reading), ${ }^{8}$ or (iii) it can participate in a scope independent reading with the given $w h$-phrase (branching, cumulative, etc. readings). Recall the analysis of (42), How did everyone behave?: (42a) is a family-of-questions reading, (42b) is an independent reading, and (42c) is the ungrammatical, narrow scope universal reading. The reason why (Relativized Minimality and) Szabolcsi and Zwarts's proposal could be descriptively almost correct is that typically, though not all and only, upward monotonic items have options (i) through (iii).

Let us first restrict our attention to quantifiers. The case of (i) is rather straightforward: Zimmermann (1991) shows that principal ultrafilters (e.g. names) are scopeless. As regards (ii), both Groenendijk and Stokhof (1984) and Higginbotham (1991) claim that all quantifiers that are not downward monotonic can give rise to a family-of-questions reading. These quantifiers have non-empty minimal elements (i.e., smallest sets $S$ of individuals such that $S \in G Q$ ); the question is to be answered for each individual in some minimal element. Definites and, in general, universals, denote filters: they have a

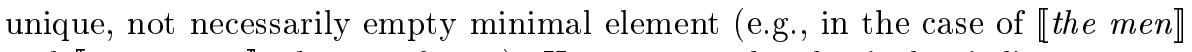

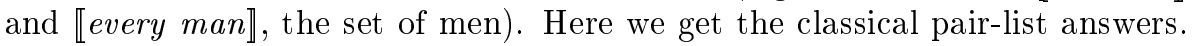
Indefinites have as a rule more than one minimal element (e.g., the minimal

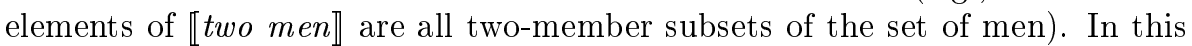
case the answerer has to choose one minimal element and give a pair-list answer for the individuals in it. Groenendijk and Stokhof call this a choice reading.

(51) Who did every man see?

Man 1 saw Mary, $\operatorname{man}_{2}$ saw Susan, $\ldots, \operatorname{man}_{n}$ saw Lynn.

(52) Who did two men see?

For instance, John saw Susan, and Bill saw Jill.

It is remarkable that according to Groenendijk and Stokhof, both exactly five men and at most five men, which were found problematic in (35), give rise

\footnotetext{
${ }^{7}$ The notion of an intervener must be defined so as to cover the type * Who didn't destroy this city?, in Section 6.1 , which shows that any item that crucially enters into the computation of an answer counts as an 'intervener,' even if it syntactically does not intervene between the $w h$-phrase and its trace. We leave open the question whether the definition is to be syntactic or semantic.

${ }^{8}$ The identification of the family-of-questions reading with the quantifier scoping over the $w h$-word is theoretically not unproblematic (see Engdahl 1985, Chierchia 1992. Nothing much hinges on this analysis in the present paper. We tentatively adopt this analysis here in part because it makes it easier to express this section's generalizations, and in part because it is supported by Hungarian. Hungarian lacks both the family of questions and the choice readings. Since the language disambiguates the relative scopes of quantifier and wh/focus phrases in surface structure, the absence of these readings can be rather straightforwardly attributed to the fact that quantifiers never take scope over WH in Hungarian (whatever the explanation should be). See Szabolcsi (1983), É. Kiss (1991).
} 
to the choice reading (the latter does because it is supposed to allow for an upward monotonic group reading). Downward monotonic quantifiers do not support the family of questions reading, since their minimal element is empty.

These generalizations need significant refinement; for instance, they do not explain the observation (de Swart's and our own) that adverbs like twice, a lot, and even always, and modified indefinites like at least two men, do not give rise to family-of-questions readings. Another salient fact to be explained is that the family-of-questions reading is not available in every language (cf. note 8 ). But even in this preliminary form they provide a partial explanation of why downward monotonic interveners were found to create weak islands. As they do not give rise to the family-of-questions readings, at least one option to "get out of the way" is unavailable to them.

As regards (iii), three kinds of scope independent readings have been noted in the literature: branching (Barwise 1979), cumulative (Scha 1981), and intermediate ones (Sher 1991).

(53) Three students read two books. (branching) 'There is a set $S$ of three students, and there is a set $B$ of two books, and every member of $S$ read every member of $B^{\prime}$

(54) Three students read two books.

(cumulative) 'There is a set $S$ of three students, and there is a set $B$ of two books, and every member of $S$ read at least one member of $B$, and every member of $B$ was read by at least one member of $S$ '

Liu $(1990,1992)$ conducted an empirical study of what noun phrases participate in branching readings in sentences like (53). She identifies a subset of noun phrases denoting upward monotonic quantifiers; she calls them G(eneralized)specific. These include definites, universals, and indefinites not modified by at least, at most, or exactly; wh-phrases are also among them. A branching analysis is always available whenever both noun phrases are G-specific. Questions that may be analyzed as exhibiting these readings are as follows: ${ }^{9}$

(55) How many circles did everyone draw? (branching) 'Everyone drew the same number of circles-how many was it?'

(56) How many circles did these two people draw? 'Altogether how many circles did these two people draw?'

\footnotetext{
${ }^{9}$ In examples like (55) the fact that uniformity is presupposed, rather than asserted, is at least as relevant as branching itself. See (110)-(11) for an analysis. The constraints on cumulative readings have not been yet been studied in descriptive detail, but for a thorough theoretical discussion, see Schein (1993).
} 
In a chapter on gradience, Szabolcsi and Zwarts (1991) observed that downward monotonic interveners create the most robust weak islands, while Liu's G-specific noun phrases are the most innocuous, even among the upward monotonic ones. These observations are immediately explained once we think about weak islands in terms of scope. Downward NPs have only a narrow scope reading, whereas G-specific NPs have the greatest number of non-narrow scope readings.

Going beyond quantifiers, note finally that intervening scopal particles (NEG) and verbs (deny, regret) have no chance to "get out of the way." * The same holds for intervening wh-phrases: if who in *How do you wonder who behaved? took matrix scope, the subcategorization of wonder would be violated.

Although much more work is needed to clarify the semantic conditions of scope interaction between $w h$-phrases and quantifiers, with this we take it that the global plausibility of the scope account is established.

\section{SCOPE, OPERATIONS, INDIVIDUALITY}

The rest of the paper is concerned with the question why certain wh-phrases cannot take wide scope and are thus sensitive to weak islands. To be able to address this question, we will first propose a way of looking at scope that allows us to infer (certain) scope-taking abilities from the denotational semantic properties of the interacting expressions. The general idea is this:

(57) Scope and operations ${ }^{\dagger}$

Each scopal element SE is associated with certain operations (e.g., not with complements). For a $w h$-phrase to take wide scope over some SE means that the operations associated with SE need to be performed in wh's denotation domain. If the $w h$-phrase denotes in a domain for which the requisite operation is not defined, it cannot scope over SE.

More specifically, we will adopt the claim, advanced in Szabolcsi and Zwarts, that the crucial property that island-sensitive wh-phrases have is that they do not range over individuals, but we interpret this very differently from Szabolcsi and Zwarts, as follows:

(58) Individuality and wide scope taking

When a $w h$-phrase ranges over discrete individuals, these can be collected

\footnotetext{
* It was noticed in Williams (1974) that stressed negatives do not create weak islands, e.g., How DIDN'T you behave? Neither we, nor the literature we are aware of has an account of this fact.

†The discussion in 5.1 will show that reference to "the wh-phrase's denotation domain" is simple but not quite precise. See the main text and the footnote there.
} 
into unordered sets. All Boolean operations can be performed on such sets. When a $w h$-phrase does not range over discrete individuals, only a smaller set of operations (possibly none) are available in its denotation domain, hence answers cannot be defined in the general case.

The discussion will proceed in the following steps. Section 5.1 outlines how (57) and (58) work in principle. Section 5.2 presents detailed empirical justification for the individual vs. ordered distinction. Section 5.3 discusses its implementation in algebraic terms, and Section 5.4 analyses some further interveners. Section 6.1 presents further empirical support for the relevance of this distinction. It will be shown that when some argument of a verb necessarily denotes a sum, it is affected by weak islands, however "referential" it may be in thematic role or discourse terms. Section 6.2 argues that whether a domain consists of sums or unordered sets depends on whether the predicate is iterable and summative in the pertinent respect. 6.2 also lays out some formal details of how answers are defined.

\subsection{Scope and operations}

Let us begin by asking what "taking wide scope" means (for present purposes, at least). Consider the following questions, on the wide scope who reading:

(59) Who did Fido see?

(60) Who didn't Fido see?

(61) Who did every dog see?

(62) Who did at least two dogs see?

We assume that the interpretation of questions, whatever it should precisely be, ensures that an exhaustive list is determined by the answer. We will be concerned with how such a list can be defined or verified. The novelty of our approach consists in presenting standard procedures in such a way that a connection is established between the denotational semantic properties of the interacting expressions and their scope possibilities. The Boolean interpretations of the scopal interveners in (60)-(62) are as follows (see Keenan and Faltz 1985, pp. 84, 229 for precise definitions):

(63) a. Negation corresponds to taking complements.

b. Universal quantification corresponds to taking intersections.

c. Existential quantification corresponds to taking unions. 
d. Numerical quantification corresponds to a combination of intersections and unions.

In the light of these, we can explicate (59)-(62) as follows.

To answer (59), we form the set of people that Fido saw, and list its members. For (60), we form the complement of this set. For (61), we take for each dog the set of individuals that it saw, intersect them, and list the members of the intersection. If (62) had at least one dog, we would simply take the sets of individuals that each dog saw and union them. The presence of two makes life more complicated: we have to take a lot of intersections in order to determine whether the same individual shows up in at least two sets, and then union the results. These cases contrast with the family-of-questions reading of (61), for instance: pair-list answers do not require Boolean operations.

The moral is that for a $w h$-phrase to take wide scope over some scopal element SE means that the definition/verification of the answer involves specific operations associated with SE.

This definition is rather general. First, it does not require for the narrow scope SE to become referentially dependent on the wide scope taker, hence SEs like negation are covered. Second, it would easily extend from wide scope $w h$ phrases to arbitrary wide scope quantifiers (at least as a necessary condition).

A simple consequence of the above is that a particular wh-phrase is able to take scope over some SE only if the requisite operations are available in the domain the $w h$-phrase ranges over. In (60)-(62) this is no problem. Persons that Fido saw denotes a set of individuals. Individuals can be collected into unordered sets. An unordered set is one that has no partial ordering defined on its elements; either because it would be impossible to define one or because we choose not to define one. Unions, intersections, and complements are defined for sets of individuals; unordered sets naturally form Boolean algebras. But are these operations available in the domains of all $w h$-phrases?

Szabolcsi and Zwarts argued that the distinctive descriptive property of island-sensitive $w h$-phrases is that they do not range over individuals but, rather, elements of partially ordered domains. We return to the empirical justification of this claim in Section 5.2. At this point, let us simply consider the following theoretical possibilities: ${ }^{10}$

(64) a. A partial ordering is a reflexive, transitive, anti-symmetric relationparadigmatically: inclusion.

b. A Boolean algebra is a partially ordered set closed under unions, intersections, and complements.

\footnotetext{
${ }^{10}$ We use the qualification 'proper' to indicate that if the definition does not require the presence of an operation, it is indeed not present. A structure is 'closed under' an operation if the result of applying that operation to any element(s) of the structure is always an element of the structure.
} 
c. A (proper) lattice is a partially ordered set closed under unions and intersections (but not complements).

d. A (proper) join semilattice is a partially ordered set closed under unions (but not complements or intersections).

e. A (proper) partial order is a partially ordered set (not closed under either complements, or intersections, or unions).

Proper lattices, join semilattices, and partial orders are thus increasingly poorer structures than Boolean algebras. From our present perspective this means that if a wh-phrase (on a certain interpretation) ranges over elements of such structures, some or all Boolean operations are unavailable in its domain. Consequently, it is predicted not to be able to take scope over SEs whose definition involves at least one of the missing operations. Thus, it is predicted to be sensitive to weak islands created by such SEs.

In Sections 5.3 and 6.1 we will argue that each of these cases is represented by $w h$-phrases. Specifically, number expressions denote in lattices, while collectives, manners, and amounts in join semi-lattices.*

${ }^{*}$ The explication of (59)-(62) and the subsequent reasoning in the main text show that the wording of (57) is not quite precise. To appreciate this, let us compare the derivations of (I wonder) who you didn't see and *(I wonder) how you didn't behave. The denotations of the you didn't see and the you didn't behave segments need to be computed first. You saw denotes the set of individuals that you saw. Then, you didn't see is expected to denote the complement of this set. Since sets of individuals form Boolean algebras, complementation is fine. Once we got this far, combining the result with who cannot be a problem. On the other hand, we argue that the denotation of you behaved should not be conceived of as the set of manners that characterized your behavior but, rather, as the manner that characterized your behavior. Then, you didn't behave is expected to denote the complement of this manner. Since we argue that manners form join semi-lattices, in which complementation is not defined, the denotation of you didn't behave cannot be computed, and the derivation cannot proceed any further.

These derivations should make clear that the operation associated with the narrow scope SE not is actually performed in the course of computing the denotation of that segment of the sentence that the overt $w h$-phrase is to combine with. What role does the nature of the wh-phrase play, then? The segment we are looking at contains a gap associated with the wh-phrase. What this segment denotes is determined by what this gap is and, by transitivity, by what the $w h$-phrase is. It is for this reason that in (57) we used the oversimplified (perhaps misleading) formulation that the operation needs to be performed in "the wh-phrase's denotation domain."

It is clear, then, that while individuals themselves are not structured and manners are, what counts here (as claimed throughout the paper) is the Boolean structure of the sets of individuals and the semi-lattice structure of manners.

Let us compare, in this light, (I wonder) who you didn't see with * (I wonder) who you didn't get this letter from. Who ranges over individuals (of type $e$ ) in both cases, but over individuals of different algebraic structures. In Section 6 we argue that you got this letter from does not denote the set of those who you got this letter from but, rather, the collective that you got this letter from. (This collective may be atomic or plural.) The standard assumption is that collectives are individuals that form join semi-lattices; hence the impossibility of 
It may be important to point out a difference between the roles this proposal and Szabolcsi and Zwarts assign to partial ordering. Take the example of idiom chunks. According to Rizzi (1990), their extraction is sensitive to weak islands because they do not have a referential index. If idiom chunks do not have any reference at all, not even of an abstract kind, then Szabolcsi and Zwarts made the wrong prediction here because such things cannot exhibit a partial order, and hence cannot be interested in its preservation. In contrast, the present proposal makes the correct prediction: idiom chunks do not refer to things that can be collected into unordered sets, whence the Boolean operations are not available for defining an answer. Partial ordering here is not the defining characteristic of island-sensitive extractees but, rather, the most typical case of lack of individuality.

Anticipating the empirical results, consider the following problem. Is it correct to insist that answers be laboriously "computed"? Instead, we could just look at every individual in our universe and check whether it exhibits the property of being seen by Fido, not being seen by Fido, being seen by every dog, and being seen by at least two dogs. Let us call this the "look-up" procedure. For look-up, the properties in (60) through (62) are as simple as the property of being seen by Fido: look-up does not really take cognizance of the fact that who is taking scope over some scopal element. Look-up is viable because we assume that each individual is a "peg," from which all its properties are hanging (cf. Landman 1986).

But this procedure cannot be general. For one thing, we certainly do not want to exclude the possibility of being able to "compute" even those things that can be looked up. On the other hand, not everything that we can talk about is a "peg." For instance, it is natural to look at the Fido-peg and find that Fido is loud and weighs twenty pounds-but it is not natural to have a loudness peg with the information that Fido is loud, or a twenty-pounds peg with the information that Fido weighs twenty pounds. (Unless, of course, we are dealing with a contextual individuation of particular weights.) This means that a question like How much do at least two dogs weigh? cannot be answered by looking at every weight peg and finding out whether it exhibits the property that at least two dogs have it. The answer has to be "computed" by manipulating information obtained by looking at dogs - and then the question whether the requisite operations are available is crucial.

We are convinced that "look-up" plays an important role in a pragmatic/procedural model (which it will be necessary to develop to account for further aspects of the weak islands phenomenon). But it does not eliminate the need for

complementation is expected. Notice that in this minimal pair predictions cannot be made by simply looking at the wh-phrase; we need to know what the predicate (and thus the gap) is. We thank P. Jacobson and D. Cresti for pointing out the need for these clarifying remarks. 
"computation," and hence it does not eliminate the vulnerability of $w h$-phrases that denote in an impoverished domain.

\subsection{Individuation: semantics versus pragmatics}

Consider a sample of wh-phrases: (i) which person(s), (ii) who, (iii) what, how many men, (iv) who/what the hell, (v) how many pounds, how much attention, how tall, how, why. Although the majority of scholars working on the subject do not examine the full sample, there is agreement that the phrases in (i) and (ii) extract most easily, and those in (iv) and (v) least easily, from weak islands. Furthermore, there is agreement that various degrees of contextualization enable practically any wh-phrase, save for why, to extract. The question is what distinguishes good and bad extractees and, in particular, what role contextualization plays. The arguments to be put forth in this section are consonant with Szabolcsi and Zwarts but are significantly more elaborate.

We argue that the crucial distinction is between $w h$-phrases that range over individuals and those that do not. We use the term individual to refer both to entities like John and Mary that are inherently discrete and to those, typically higher order, objects whose natural overlaps and complements we expressly choose to ignore. It follows that individuals can naturally be collected into unordered sets (cf. Section 5.1); in fact, this is what we take to be their defining property. Non-individuals are then characterized by the fact that they exhibit a partial ordering and this ordering is indeed taken into account; or else they are strictly non-referential, e.g., idiom chunks.

In our view, contextualization (Discourse-linking) comes into play in two main ways: a salient checklist or relevance criterion (i) may individuate a naturally ordered domain, and/or (ii) may speed up the manipulation of an already individual domain by making "look-up" available. For instance, (i) is the case in (65a):

(65) a. What don't we have good supplies of? Just bread and juice.

Contextualization is necessary not only to allow us to exclude, say, fire engines and phlogiston from consideration, but also to free us from listing supercategories and subcategories of bread and juice that we do not have good supplies of. Here contextualization saves a potentially unanswerable question. Similarly in $(65 \mathrm{~b})$, which is acceptable if we have a list of potential scores and receivers' names on the blackboard:

b. How many scores did no one receive? (Answer: 22 and 27.)

'Which of the figures on the blackboard has no name next to it?'

On the other hand, (ii) is the case in (66) when who ranges over persons under discussion: 
(66) Who did everybody support? The candidate from Ohio.

When possible, it is indeed much faster to check a finite set of "candidate pegs" and see which of them have the property of being supported by everybody than to construct the intersection of everybody's supportees, as was described in Section 5.1. Here contextualization merely makes a question more felicitous.

These may be regarded as classical cases of D-linking: what, how many, and who now range over members of some salient set. What we wish to stress here is that what on its property reading can only do this if we make the strictly semantic move of collecting properties into an unordered set, i.e., if we expressly ignore the partial ordering that is otherwise inherent to them. Similarly for how many scores. Our explanation of the weak island phenomenon rests on this semantic aspect of individuation. ${ }^{11,12}$

Perhaps the clearest evidence that ranging over individuals, rather than ranging over contextually salient items, is the critical factor in extraction is provided by Dobrovie-Sorin (1992), whose views on this matter are very similar to ours. She discusses three distinct interpretations of how many-phrases: amount (67a), non-D-linked individual (67b), and D-linked individual (68). Dlinked human direct objects in Romanian are clitic-doubled, which is extremely helpful in distinguishing readings (67b) and (68). The contrast in (67a, b) shows that 'how many women' on the amount interpretation cannot extract from a factive island, but on the individual interpretation it can extract even if it is not D-linked, i.e., not clitic doubled: ${ }^{13}$

(67) Cîte femei regreţi câ ai iubit? how-many women regret-you that have loved

\footnotetext{
${ }^{11}$ The present notion of individuals is the same as in Szabolcsi (1983), a discussion of the focusing of Hungarian bare singulars in Montague Grammar. Our references to answerability are intuitively very compatible with Comorovski (1989). But she makes use of it technically in a very different way than we do. Restricting her discussion of weak islands to extraction from embedded constituent questions, she claims that a sentence like Who do you know who invited? presupposes that everybody was invited by someone. The question is not answerable unless this presupposition can be checked; and it is not checkable unless who ranges over a set of known membership. Thus our cases (i) and (ii) are on a par for Comorovski, even though who, as opposed to property-what, is independently capable of ranging over individuals. Furthermore, even if the presuppositional analysis of questions is correct, it is not clear how Comorovski's theory would extend to all the weak island cases that we intend to generalize over. For a discussion of referentiality, see also Chung (1992).

${ }^{12}$ The existence of individual correlates of properties (cf. Chierchia 1984) does not seem to automatically immunize properties against weak islands, as was pointed out to us by Alessandro Zucchi.

${ }^{13}$ Dobrovie-Sorin (1992) makes the crucial distinction in terms of restricted versus nonrestricted quantification. Caveat: Dobrovie-Sorin paraphrases (67) on the (a) reading using the phrase 'for what number.' We changed this because in Section 5.3 we will argue that numeral expressions have a 'numbers' reading, distinct from the 'amount' reading.
} 
a. * 'For what amount of women, you regret having loved that amount of women?' (Answer: Three.)

b. 'How many women are there such that you regret having loved them?' (Answer: There are three such women.)

(68) Pe cîte femei regreţi câ le ai iubit? prep how-many women regret-you that $\mathrm{cl}$ have loved 'How many [=which] of the women do you regret having loved?' (Answer: Three of them, namely, A, B, and C.)

Other authors who identify individualhood as the crucial factor (although for somewhat different reasons) are Aoun (1986) and Frampton (1990).

In the rest of this section we will provide informal empirical support for the claim that the core examples of island-sensitive extractees can be described as non-individual (partially ordered), and that the behavior of wh-the-hell expressions is also accountable for without making crucial reference to D-linking.

Wh-phrases like which person can easily be taken to range over individuals (as can plural which persons, as long as the predicate is distributive; certain nondistributive cases will be taken up in Section 6.1). Both who and what can range over individuals. But what (and marginally even who) also ranges over properties, which are ordered; see above. Why requires a propositional answer, and propositions are ordered by entailment, a special case of inclusion. ${ }^{14}$

How many $N$ phrases have an individual interpretation but also, like how many pounds and how much attention, an amount interpretation (cf. 67a). Amounts can only be made sense of in terms of an ordering. The individual vs. amount ambiguity of numeral phrases is highlighted by the presence or absence of copula agreement in Italian clefts (an observation we owe to Filippo

\footnotetext{
${ }^{14}$ In the eighties why was the paradigmatic example of island-sensitivity, but it seems to us that it is in fact rather atypical. Its extraction is blocked by a wider range of interveners than that of any other wh-phrase. For instance,

i. Why did at least three men leave?

'Why did three, rather than only two, men leave?

* 'What reason did at least three men have for leaving?'

ii. Why did you want me to quit?

'What reason did you have for wanting me to quit?'

* 'What reason did you want me to have for quitting?'

Informally, we may say that why is "captured" by the closest "interesting" thing in its own clause. This seems true even of German warum, which differs from why in being able to remain in situ (T. Kiss 1991; H. van Riemsdijk, p. c.). For this reason we will avoid whyexamples. We have no account of its peculiar behavior for the time being.

On the formal side, note that the Boolean algebra associated with the propositional calculus consists of equivalence classes of propositions (usually referred to as the Lindenbaum algebra). The calculus itself is not Boolean in nature.
} 
Beghelli). The agreeing version (a) is insensitive to weak islands, while the non-agreeing version (b) is sensitive:
a. Sono cinque donne che non ho invitato.
are five women that not have-I invited
'There are five women who I didn't invite'

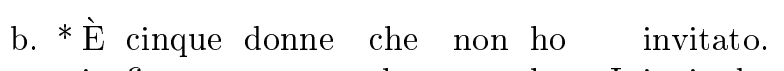

is five women that not have-I invited

'The amount such that I didn't invite that many women is five'

In French, combien-extraction unambiguously invokes the amount interpretation, although it is not a necessary condition for it:
a. Combien de livres as-tu beaucoup consulté?
how-many of books have-you a lot consulted
'How many books are there that you have consulted a lot' or
'How many of the books have you consulted a lot?'
b. * Combien as-tu beaucoup consulté de livres? how-many have-you a lot consulted of books 'For what amount, you consulted that many books a lot?'
c. * Combien de cercles as-tu beaucoup dessiné? how-many of circles have-you a lot drawn 'How many circles did you draw a lot? [OK if circle-types]'

We argue that manners, the domain of how, are also ordered; in particular, the components of the manner characterizing each event do not form a set but a sum. ${ }^{15}$ This intuition can be corroborated by a test involving only. Only has two interpretations: 'exclusively' and 'merely'. The first applies to elements of unordered sets, the second to elements of ordered ones. They may differ in their syntax (see Harada and Noguchi 1992); some languages even have different words for them. ${ }^{16}$ See (71) for German and (72) for Dutch:
a. Johann war nur 1953 und 1958 in London.
John was only 1953 and 1958 in London
'John was in London only (= exclusively) in 1953 and 1958'
b. Johanns Sohn wurde erst 1990 geboren.
John's son was only 1990 born
'John's son was born only (= as recently as) 1990'

\footnotetext{
${ }^{15} \mathrm{~A}$ sum is a nonminimal element of a join semilattice; see the next subsection.

${ }^{16}$ Some claim that alleen in (72a) is an independent adverb (whereas slechts is part of the subject). But Alleen drie mannen woonden de vergadering bij 'Only three men were at the meeting' is fine, and alleen is part of an XP in first position.
} 
a. Er zijn alleen drie stoelen in de kamer. expl is only three chairs in the room 'There are only three chairs (and nothing else) in the room'

b. Er zijn slechts drie stoelen in de kamer. expl is only three chairs in the room 'There are only three chairs (and no more) in the room'

We observe that Dutch alleen means 'exclusively' and slechts 'merely'. They can thus serve to diagnose adverbs:

a. ${ }^{*}$ Hij heeft het probleem om 2:00 alleen elegant opgelost. he has the problem at 2:00 only elegantly solved 'He solved the problem at 2:00 only [= exclusively] elegantly'

b. ? Hij heeft het probleem om 2:00 slechts elegant opgelost. he has the problem at 2:00 only elegantly solved 'He solved the problem at 2:00 only [= merely] elegantly'

c. Hij heeft het probleem om 2:00 slechts met tegenzin he has the problem at 2:00 only with reluctance opgelost. solved 'He solved the problem at 2:00 only [= merely] reluctantly'

d. Zijn hele leven, heeft hij problemen alleen/*slechts his whole life has he problems only elegant opgelost. elegantly solved 'In all his life, he solved problems only [= exclusively] elegantly'

(73a) with alleen elegant is unacceptable because the components of the manner in which the problem was solved on a particular occasion do not form a set; alleen elegant cannot mean 'of all manners, only elegantly'. (73b) with slechts elegant is somewhat strange, since elegance is towards the high end of the scale; (73c) with slechts met tegenzin is fine, since reluctance is towards the low end. (73d) switches to a bare plural object, whence we have a plurality of problem-solving events. Each has a manner of its own, and these manners as wholes can be collected into a set. Here alleen elegant can be used: it means that the manner of every problem-solving was elegant. The judgments are the same for the English counterparts. There is a corresponding improvement in extractability:
a. * In what way didn't you solve the problem at 2:00?
b. In what way did you never solve problems? 
(74a) may be acceptable, too, if the manner domain is turned into an unordered set by the brute force of D-linking, i.e., by providing an explicit list of manners to check and to report on in the answer.

The next question to ask is whether there remain cases that make invoking D-linking truly indispensable. Wh-the-hell expressions are a good candidate. Since Pesetsky (1987) it has been assumed that they form minimal pairs with their plain counterparts in that they are "aggressively non-D-linked," whereas plain wh-phrases are D-linkable. They seem to make a strong case for D-linking since they extract markedly less well than their counterparts, even when they contain individual expressions like who:

a. Who are you wondering whether to invite?

b. ?? Who the hell are you wondering whether to invite?

We wish to argue that D-linkability is not a minimal difference between wh-thehell expressions and their plain counterparts. Consider the following pair:

(76) a. Who saw John on the way home?

b. Who the hell saw John on the way home?

Let us ignore the rhetorical or cursing uses of (76b). Even so, the contexts in which the two questions are usable are not the same. The existential presupposition wh-questions carry does not prevent (76a) from being an open question, readily answerable by Nobody. (76b) on the other hand can only be asked if we have unquestionable evidence that someone saw John, and merely wish to identify the person(s). The strength of this requirement is illustrated by a context we owe to Bruce Hayes. When asked what a felicitous use of Who the hell saw his mother? would be, he answered, "If we know that whenever someone sees his mother, God sends purple rain, then upon seeing purple rain, I can ask: Who the hell saw his mother?" Now, lacking institutions like purple rain, we typically do not have unquestionable evidence about the rather complex situations that weak island violations tend to describe, e.g., that you are wondering whether to invite a particular person (cf. 75b). This provides an explanation of why such questions are notoriously bad. On the other hand, in those special situations where we do have such evidence, the wh-the-hell expressions become acceptable; for example, seeing someone madly searching through the dictionary, we may ask (77); or, one thief, seeing another trying to smuggle an item back to a house just robbed, may ask (78):

(77) What the hell do you still not know how to spell?

(78) What the hell are you upset that you took? 
Tetsuya Sano (p. c.) informs us that these intuitions are paralleled by the interpretation and behavior of ittai-phrases in Japanese. We interpret these data as indicating that D-linking is not the critical factor in the behavior of wh-the-hell expressions; they are bad extractees for independent reasons.

These remarks have been intended to support the claim that the crucial feature of island-escapers is semantic. It appears that discourse context never makes a minimal difference for extractability. D-linking plays an important role when it forces, and facilitates, the individuation of a domain that is originally not individuated; but it is the ensuing semantic change, the creation of an unordered set, that matters for extractability. ${ }^{17}$

\subsection{Structures for manners, amounts, and numbers}

We assume that on the individual interpretation of who, what, how many men, etc. these expressions range over elements of unordered sets, whether or not they are D-linked: they invite us to list, or count, the members of such sets. Their immunity to weak islands is accounted for with reference to the fact that all Boolean operations are defined for unordered sets. (79) below illustrates the structure of a tiny Boolean algebra for sets of individuals:

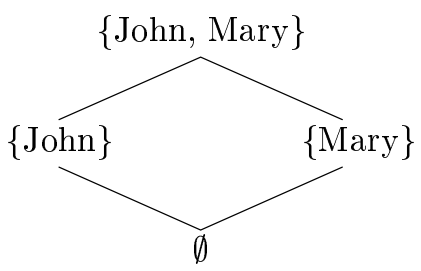

In this section we propose specific denotation domains for some island-sensitive phrases and show that they lack some or all of the Boolean operations. (The "domain" of idiom chunks trivially lacks the Boolean operations as they have no mentionable denotation at all).

The following structures will be considered; each is annotated with the kinds of expressions/readings we propose to assign to such a domain. The qualifi-

\footnotetext{
${ }^{17}$ There are significant cross-linguistic differences in the behavior of wh-phrases, which cautions against the careless use of "dictionary equivalents." Just two examples. English which is rather strictly D-linked; Dutch welk(e) and Hungarian melyik are much less so: they only require unicity. E.g., In what year were you born? is neutrally put as Melyik évben születtél? 'In which year were you born?' It is interesting to observe that welk(e)/melyikphrases are just as good extractees as more D-linked which-phrases. Or, English when does not seem to be able to range over individuals even in D-linking contexts, whereas Hungarian

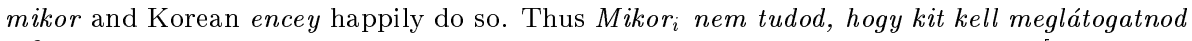
$t_{i}$ ? and ne-nun nwukwu-lul encey pangmwunha-eyaha-nunci al-ko sip-ni "When [= on what holidays] don't you know who you have to pay a visit?' are acceptable, in contrast to their English counterpart.
} 
cation 'proper' is understood throughout; $\oplus$ stands for sum-formation, viz., semilattice unions: ${ }^{18}$

(80) Free Join Semilattice

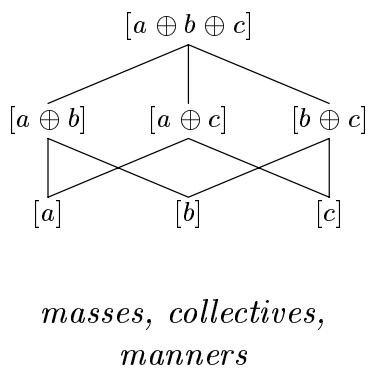

(81) Join Semilattice

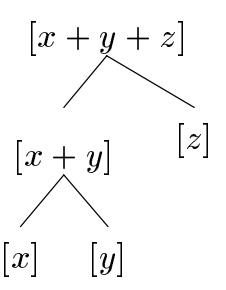

amounts
(82) Lattice

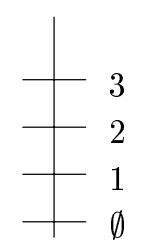

numbers

The structure (80) has been proposed as the denotation domain of mass terms and plurals-as-collectives (see Landman 1991, pp. 254-267; 317-324 for a summary). We propose to add manners. Masses do not concern us in this paper; collectives will be explored in the next section. (81) and (82) have not received much attention in the literature. We argue below that numeral expressions on the amount reading denote elements of non-free join semilattices, whereas on the number reading (not yet discussed) they denote elements of chains, a special case of lattices.

The assumption of these structures leads us to predict that different extractees are sensitive to different interveners. ${ }^{19}$ (80) and (81) have no bottom element (one that is smaller than any other in the structure). Hence they cannot be closed under complements (the complement of the top element $[a \oplus b \oplus c]$ or $[x+y+z]$ should be $\emptyset$ ) and under intersections (the intersection of two disjoint elements should be $\emptyset$ ). Both (80) and (81) are closed under unions, but only (80) is a fully articulated free structure. (Freedom means that whenever two pairs of elements are distinct, their unions are distinct, whereas in (81) [y] and $[z]$ have no union distinct from $[x+y+z]$, for instance.) Thus collectives, manners, and amounts are predicted to be sensitive to weak islands created by SEs whose definition involves complements or intersections, but not to SEs involving just unions. (That is, if they turn out to be sensitive to the latter type, too, this must have an additional reason.) Finally, the chain in (82) is closed under unions (the least upper bound of 1 and 2 is 2) and, since it has a bottom element, it is closed under intersections as well (the greatest lower

\footnotetext{
${ }^{18}$ To make the discussion accessible to readers who are only familiar with the elements of set theory, we will talk about "union" and "intersection" even when technically, we should say 'join' and 'meet.'

${ }^{19}$ One might call this a truly semantic relativized minimality effect: the meaning of each extractee determines what interveners it is sensitive to.
} 
bound of 1 and $\emptyset$ is $\emptyset$ ); it qualifies as a lattice. Note that it has no top element and cannot be closed under complements. Thus numbers are predicted to be sensitive to weak islands involving complements only.

Let us consider these cases one by one.

The fact that the join semilattice (80) is closed under unions expresses the cumulative reference property of masses and collectives. Section 6.1 will demonstrate that collectives are indeed sensitive to islands requiring complements or intersections. Do manners also denote elements of a join semilattice? We argued in Section 5.2 that they exhibit some partial ordering. It may be added that the ordering must be by unions, not intersections. If John behaved nicely but stupidly, his behavior is not one that has just the features common to niceness and stupidity but, rather, a behavior that subsumes both. ${ }^{20}$ We have seen that how-extraction is sensitive to the standard weak islands, negative islands among them; moreover, that how does not take scope over a universal. To recapitulate the relevant observation in (42c), imagine that Bill behaved rudely and stupidly, Mary loudly and stupidly, and John nicely and stupidly; that is, everyone's complex behavior had stupidity to it. Under such circumstances, the question How did everyone behave? can nevertheless not be answered by Stupidly. This indicates that manners denote in (80) or in a mere partial order, the choice depending on whether we assume closure under unions or merely the existence of some unions. Intuitively, the sum of any two behaviors seems like a good candidate for being a more complex behavior, possibly including contradictory cases like kindly and unkindly. In accordance with this, questions in which how needs to take scope over a plain existential sound acceptable: ${ }^{21}$

(83) How did at least one person behave?

We will therefore assume that how denotes in a join semilattice (cf. 80).

Next, consider how many $(N)$. Its individual reading (D-linked or not) has been discussed in Section 5.2; now we are concerned with its non-individual

\footnotetext{
${ }^{20}$ It is another matter whether the people who behave nicely but stupidly are in the intersection of those who behaved nicely and those who behaved stupidly. This depends on whether behave is taken to be distributive. If not, only a weaker relation will hold: that of having niceness to one's behavior. This weaker relation is comparable to a situation in which, if John and Bill lifted the table together, John did not lift the table but he participated in lifting the table.

${ }^{21}$ What is the answer to (83) in the situation sketched in connection with (42c)? Rudely and stupidly, loudly and stupidly, and nicely but stupidly may not sound acceptable. This may have an independent reason; in Section 6.2 we argue that the behave-relation is not summative. This problem can be avoided by answering, At least one person behaved rudely and stupidly, at least one loudly and stupidly, and at least one nicely but stupidly. Note that this is not a pair-list answer since it does not name the subjects (the first members of the pairs). If this reasoning is acceptable, manners indeed denote in a join semi-lattice. If not, we may assume, for instance, that some "contradictory" behaviors are impossible, whence we do not have closure under unions, and manners will be assigned some proper partial order. Nothing much seems to hinge on whether manners end up in (80).
} 
readings. They come in two varieties: the well-known amount reading, as was given in $(67 \mathrm{a})$ for Romanian and $(70 \mathrm{~b}, \mathrm{c})$ for French, and what we will call the number reading.
a. * Cîte
femei regreţi câ ai iubit?
how-many women regret-you that have loved
'For what amount of women, you regret having loved that amount of women?' (Answer: Three.)
b. * Combien as-tu beaucoup consulté de livres? how-many have-you a lot consulted of books 'For what amount, you consulted that many books a lot?'
c. * Combien de cercles as-tu beaucoup dessiné? how-many of circles have-you a lot drawn 'How many circles did you draw a lot? [OK if circle-types]'

Although the amount reading is well-known, there is no standard algebraic structure for it in the literature. The join semilattice discussed above does not seem to offer a way to capture the measuring aspect of amounts. The simplest alternative might be to turn to the chain of natural numbers. But that has too rich a structure: being a lattice, it lacks only complements. On the other hand, amounts seem sensitive to the intersections as well, cf. de Swart (1992):
a. * How many circles did no kid draw?
b. * How many circles did every kid draw?

This shows that amounts denote in a poorer structure, possibly (81). Our argument now will proceed in two steps. We first argue that although (82) is not appropriate for the amount reading, it does correspond to another nonindividual reading of numeral expressions. With this reading out of the way, we go on to justify the adoption of (81) for amounts.

It appears that there are contexts in which a non-individual how many $N$ is able to take scope over universals and numerals. We may informally characterize these contexts as "counting-conscious." Suppose that we are evaluating how appropriate the midterm test was in comparison with the level of the class. We may then ask questions like,

a. How many problems did every student solve?

'For what number, every student solved at least that number of problems?'

b. How many problems did at least $50 \%$ of the students solve?

'For what number, at least $50 \%$ of the students solved that number of problems?' 
Here how many problems is not D-linked: it is not intended as 'which of these problems' or 'which of the numbers that we have listed'; nor is it meant as 'how many problems are there such that ....' It asks for a purely numerical value; we will call it the number reading. Or, imagine a situation in which individuation is rather inconceivable: we agreed that the swimming team can take a break when everybody covers at least 50 laps. Feeling that the break is drawing closer, we may ask,

(86) [At least] How many laps has every swimmer covered by now?

One interesting aspect of these examples is that the narrow scope universal does not make them unacceptable. Another is that they require maximal answers. If every student solved 23 problems (but not everyone solved more) or every swimmer has covered 46 laps (but not everyone has covered more), the answerer cannot play it safe by answering One/Ten; the answers have to be Twenty-three and Forty-six, respectively. The question arises whether this is a semantic effect or a Gricean one. The adoption of the lattice structure (82) predicts that it is semantic. The narrow scope universal requires that we take intersections, which just gives the greatest lower bounds 23 and 46 in these cases.

In sum, the chain in (82) has linguistic relevance but, exhibiting the rich structure numbers have, is not appropriate as a denotation domain for islandsensitive amounts. What we need is a structure that resembles (82) in that it allows for an interpretation of measuring but is nevertheless not a chain. We argue that the structure in (81) may do the job. Below the nodes are annotated with $(=n)$ to highlight the intended interpretation:

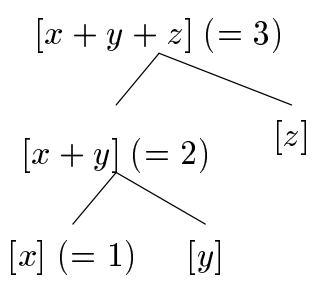

The "backbone" of (81) is a chain like (82). Formally, we may look upon (81) as a witnessed version of (82): if $p$ is a proper part of $q$, there is some part of $q$ (the witness) that does not overlap with $p$ (Landman 1991, p. 314). The branching that the witness property guarantees is sufficient to eliminate closure under intersections, which is what we are aiming at.

But what is the intuitive content of (81)? We propose that (81) is an abstraction of (80). The elements $[a],[b],[c]$, etc., in (80) represent real stuff, therefore the sum of $[a]$ and $[b]$ needs to be distinguished from the sum of $[a]$ and $[c]$ : even if they happen to have the same size, they have their own identity. 
What we do in (81) is take away the identity of bits of stuff (we might say "individuality" in the everyday sense, were 'individual' not a technical term with a different meaning in this paper). Here $[x],[y]$, $[z]$, etc., are all unitsized, though they are not unit-sized bits of concrete stuff, but arbitrary-and therefore abstract-unit-sized bits. Fixing an arbitrary unit-sized $[x]$ to start with, $[y]$ stands for the equivalence class of all unit-sized bits of stuff whose addition to $[x]$ yields a two-unit-sized bit, and $[z]$ stands for the equivalence class of all unit-sized bits of stuff whose addition to $[x+y]$ yields a three-unitsized bit. Thus amounts are construed as abstract bits of stuff. Being abstract and allowing for the definition of a scale, (81) resembles (82) more than it does (80). On the other hand, the witness property seems to capture what distinguishes amounts from numbers. (81) reflects the intuition that three cups of milk (or three men) is obtained by adding another cup of milk to two cups of milk (or another man to two men), rather than just moving higher on a scale. ${ }^{22}$

\subsection{Operations for further interveners}

So far we have primarily restricted our attention to scopal interveners that are straightforwardly Boolean (compounds). Increasing the descriptive coverage significantly would go beyond the scope of this paper; for instance, we do not present an analysis of the most famous of weak islands, i.e., wh-islands, although we believe that they belong here. ${ }^{*}$ Some discussion of two specific cases may be methodologically interesting, however.

According to Cinque (1990), complements of factives are one paradigmatic type of weak islands. Recall, however, Hegarty's (1992) observation that the empirically correct class of predicates is, rather, one that comprises Cattell's (1978) response stance and non-stance verbs, in distinction to volunteered stance ones (on the intended readings):

(37) Response stance: deny, accept, agree, confirm, verify, admit

(38) Non-stance: know, regret, remember, surprise, realize, notice

(39) Volunteered stance: think, believe, suspect, allege, assume, claim

\footnotetext{
${ }^{22}$ We follow Krifka (1990) in taking man as a measure for men. We leave open the question exactly how amounts without canonical measures should be treated, e.g., (how) much attention.

*We might adopt Groenendijk and Stokhof's (1984) semantics for interrogatives, according to which in a world where John and Mary walk, Who walks? denotes $\lambda x[\operatorname{walk}(x)]=$ \{john, mary\} (see Szabolcsi 1996 for a review, and Gutiérrez Rexach 1996 for an alternative way to get the same effect). Although Groenendijk and Stokhof do not analyze who as a quantifier, they point out that this analysis of the interrogative is equivalent to assigning universal force to the $w h$-phrase, $\operatorname{cf} . \forall x[\operatorname{walk}(x) \leftrightarrow x=$ john $\vee x=$ mary]. Thus $w h$-islands can be expected to be at least as bad as islands created by everyone.
} 
Does this mean that under the present approach the accommodation of these facts requires an in-depth analysis of the meanings of these verbs? It does not: it is sufficient to identify one Boolean operation in their meanings that is not defined for the domain of sensitive wh-phrases; a circumstance that makes the present enterprise globally feasible.

Dukes (1992) presents a preliminary analysis in this spirit. He observes that a sentence with a factive matrix predicate can be paraphrased as follows:

(87) I regret that John left. regret(I)(that John left) \& fact(that John left)

According to this analysis, the proposition that John left is an argument of both the matrix verb and the sentential predicate fact. Following Molnár (1982) and Sántha (1980), this approach naturally extends to non-factive examples in (37) and (38). For instance, fact in (87) can be replaced by some predicate like assumption in (88):

(88) I confirm that John left. confirm(I)(that John left) \& assumption(that John left)

The relevant point here is that the paraphrase involves conjunction, viz. intersection. This may be identified as the Boolean operation that creates a weak island. On the other hand, there are no natural sentential predicates for complements of volunteered stance verbs; at best a tautological cognate can be found, in which case the conjunction is semantically irrelevant:
a. I thought that John left. think(I)(that John left) \& thought(that John left)
b. I suspected that John left. suspect(I)(that John left) \& ???(that John left)

Therefore, the analysis of volunteered stance verbs does not necessitate this kind of conjunction, wherefore these contexts are predicted not to create weak islands.*

Another case that deserves mentioning is that of intensional verbs like want and seek. The standard assumption is that they are scopal elements. Nevertheless, they obviously do not create weak islands:
a. How many circles do you want to draw?
b. How many unicorns are you seeking?

\footnotetext{
${ }^{*}$ D. Dowty (p.c.) points out that if all presuppositions are represented as conjuncts, we make a host of incorrect predictions. Moltmann's (1994) event-based analysis of attitude reports provides a framework within which the proposal in the main text can be naturally implemented and avoid this problem.
} 
This is predicted by the current theory if we assume that the scopal properties of these verbs are not Boolean in nature-which seems correct. (Note that no theory that treats scope as a primitive can make the correct distinction here.)

\section{ISLAND-SENSITIVE COLLECTIVES AND THE CONDITIONS FOR SET FORMATION}

\subsection{Unique arguments and weak islands}

In this section we will discuss a set of extractees which have not been considered in previous literature and which, as far as we can see, share nothing else but the lack of Boolean structure with the standard items discussed so far, and are nevertheless systematically subject to weak islands. The distinction between iterable and 'one time only' predicates is familiar from the aspectual literature. For instance, show this letter to Mary and get a letter from Mary are iterable: it is possible to show the same letter (token) to Mary, or to get a letter from Mary, more than once. Get this letter from Mary, burn this letter, and win the Rimet Cup in 1978 are 'one time only' predicates: it is not possible to get the same letter (token), or to burn the same letter (token), more than once; similarly for winning the Rimet Cup, a unique object, in a given year. But get one's favorite letter from Mary is again not a 'one time only' predicate, due to the bound variable.

Here we will be concerned with a specific consequence of the 'one time only' property, namely, that it imposes a unicity requirement on the arguments and the adjuncts of the predicate. This can be demonstrated as follows. In the iterable (91) examples the distributive answer John did and Bill did is as acceptable as John and Bill did. In 'one time only' (92), the former is unacceptable: John and Bill must form a collective recipient . Similarly, in (91) the short (exhaustive) answer Bill can be modified by only. In (92) it cannot or, more precisely, if only is acceptable, it must mean 'alone' and not 'exclusively'. The effect disappears in (93).

(91) a. Who showed this letter token $_{\text {to }}$ Mary?

John and Bill did / John did and Bill did.

Bill did / Only Bill did.

b. Who got a letter from Mary?

John and Bill did / John did and Bill did.

Bill did / Only Bill did. 
a. Who got this letter ${ }_{\text {token }}$ from Mary?

John and Bill did / *John did and Bill did.

Bill did / (*)Only Bill did.

b. Who burned this letter ${ }_{\text {token }}$ ?

John and Bill did / *John did and Bill did.

Bill did / (*)Only Bill did.

c. Who won the Rimet Cup in 1978 ?

Argentina did / * Only Argentina did.

(93) Who got his favorite letter from Mary?

John and Bill did / John did and Bill did.

Bill did / Only Bill did.

The same observations apply to other arguments and adjuncts, e.g.,

(94) From whom did you get this letter ${ }_{\text {token }}$ ?

From Mary / (*)Only from Mary.

(95) When did you get this letter ${ }_{\text {token }}$ ?

Yesterday / Only yesterday [= not earlier $]$.

This phenomenon, together with its consequences for scope, was observed in Szabolcsi (1986, pp. 334-7). In what follows we will somewhat enlarge the set of data and spell out the explanation in terms of the present proposal.

(96) and (97) indicate that the who subject or experiencer of an iterable predicate can take scope over negation or a universal, while the who subject or source of a 'one time only' predicate cannot. (An existential would eliminate the 'one time only' property in the latter case, so it cannot be tested.) (98) and (99) show a similar contrast with a factive and a wh-island; a PP argument is extracted in order to eliminate irrelevant difficulties with subject extraction.

(96) a. Who didn't show this letter token $_{\text {to }}$ Mary?

To whom didn't you show this letter token? ?

b. * Who didn't get this letter ${ }_{\text {token }}$ from Mary?

* From whom didn't you get this letter ${ }_{\text {token }}$ ?

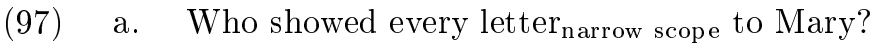

To whom did you show every letter ${ }_{\text {narrow scope }}$ ?

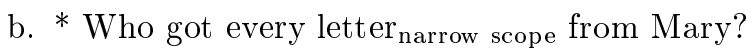

* From whom did you get every letter ${ }_{\text {narrow scope? }}$ ?

a. To whom do you regret having shown this letter token $_{\text {? }}$ ? 
b. * From whom do you regret having gotten this letter ${ }_{\text {token }}$ ?

$$
\begin{aligned}
& \text { a. To whom do you wonder whether I showed this letter } \text { token }_{\text {? }} \\
& \text { b. * From whom do you wonder whether I got this letter } \text { token } \text { ? }
\end{aligned}
$$

The sensitivity of these arguments to weak islands cannot be explained with reference to thematic roles or discourse factors. The thematic roles are equally "referential" in all cases, and there can hardly be a coherent notion of D-linking or specificity that would distinguish the 'one time' arguments from the others. On the other hand, the absence of the unicity requirement means that show this letter $_{\text {token }}$ to Mary denotes a set of individuals of whom the predicate holds independently, whereas the presence of the unicity requirement means that get this letter $r_{\text {token }}$ from Mary denotes a sum of whose parts the predicate does not hold independently:

(100) $\iota x[$ get this letter from $\operatorname{Mary}(x)]=[$ John $\oplus$ Bill $]$

Since sums form a semilattice, the explanation in the previous section carries over.

A last interesting point to note here is that exactly the same effect is observed no matter whether the sum-term is a subject or a source, although in the former case negation and the object universal do not syntactically intervene between the $w h$-phrase and its trace. This supports the definition of wide scope taking given in the previous section, which refers to the necessity of performing certain operations in the definition/verification of the answer, rather than to the wide scope taker's binding a variable within the syntactic scope of the other operator.

\subsection{Event structure and set formation}

In this section we propose a connection between certain properties of predicates and the question whether the denotation of a particular parameter is an element of an ordered or of an unordered set. 'Parameter' serves as a cover term for both arguments and adjuncts in the grammatical sense. Details of how question interpretation is defined will also be made more precise, although we are not offering a full formalization here.*

The basic idea derives from Carlson's (1984, p. 274) suggestion that bearers of thematic roles are unique per event. "If there is a proposed event with, say, two themes, then there are (at least) two events and not one." Informal though his proposal is, Carlson is careful to note that on the group reading of John and Bob threw the chest into the ocean we have a single event with the collective of

\footnotetext{
* In this section, a few changes have been made in the formalization to enhance its readability. They do not affect the content of the claims.
} 
John and Bill as its unique Agent, and in Bob washed the car, the car is the Theme, and its parts are not.

We dub events characterized by thematic uniqueness minimal events $\left(e_{m / i}\right)$ :
a. $\operatorname{visit}([$ Rome $])([\mathrm{John}])\left(\left[e_{m / i}\right]\right)$
entails (b), (c)
b. $\iota x\left[\operatorname{visit}([\right.$ Rome $\left.])(x)\left(\left[e_{m / i}\right]\right)\right]=[\mathrm{John}]$
c. $\iota x\left[\operatorname{visit}((x)[\mathrm{John}])\left(\left[e_{m / i}\right]\right)\right]=[$ Rome $]$

Enclosed in square brackets are objects coming from "overpopulated" Linkean domains (join semilattices) of various sorts. In adherence to Carlson's intuition, [John $\oplus$ Bob], i.e., the sum of John and Bob, is used only if the predicate does not distribute over the parts of the plural object. We will call semilattice objects "slobjects" and usually suppress the square brackets. How do we come to think of the denotations of visited Rome and John visited as sets of slobjects? We submit that the reason is that these predicates allow us to lump several minimal events together and, at the same time, to collect the unique slobjects corresponding to the pertinent parameter into an unordered set. This requires that the relation between events and objects be summative: ${ }^{23}$

(102) A relation $R$ [between events and objects] is summative iff

$$
R(e, x) \wedge R\left(e,{ }^{\prime} x^{\prime}\right) \rightarrow R\left(e \cup e,{ }^{\prime} x \cup x^{\prime}\right)
$$

Visited Rome is summative: If John visited Rome and Bill visited Rome, then John and Bill visited Rome-according to the present intuition, the last clause describes a non-minimal event. Similarly for John visited. We assume that summativity has to be non-vacuous: it presupposes that it is possible for there to be two distinct events that we can lump together. If the description of the predicate itself involves a parameter, then this means the relation has to be iterable with respect to that parameter. It must be possible for there to be two distinct events involving the same object:

(103) A relation $R$ [between events and objects] is iterable iff

$$
\diamond \exists e \exists e^{\prime} \exists e^{\prime \prime} \exists y\left[e^{\prime} \subseteq e \wedge e^{\prime \prime} \subseteq e \wedge e^{\prime} \neq e^{\prime \prime} \wedge R\left(e,^{\prime} y\right) \wedge R\left(e^{\prime},{ }^{\prime} y\right)\right]
$$

The $x$ visited relation between a minimal event and Rome is iterable. On the other hand, the $x$ destroyed relation between a minimal event and Rome is not iterable (in the token sense to which we adhere): the same city cannot be destroyed more than once.

\footnotetext{
${ }^{23}$ This definition as well as (103) and (116) are borrowed from Krifka (1990).
} 
Non-iterability means that the predicate describes a biunique relation between slobjects and minimal events. We encode this by writing the event parameter as a function of that other parameter with respect to which the event is not iterative:

(104) destroy(Rome)(Bob) $\left(f_{e}(\right.$ Rome $\left.)\right)$

(The agent may be so written, too, but it does not seem necessary.)

Prior to proceeding to events involving manners and amounts, let us see how the above assumptions are utilized in set formation. We will use 'set' to mean unordered set, unless otherwise specified.

We stipulate that set formation takes place only if the predicate is both summative and iterable. On the basis of (101) we can form the standard denotation of the predicate visit Rome, the set of those who visit Rome, as follows:

(105) $\left\{x: \exists e\left[e\right.\right.$ is the sum of minimal events $e_{m / i}$ of visiting Rome within some fixed event range $I \quad \& \quad x$ is the unique agent of some $\left.\left.e_{m / i} \subseteq e\right]\right\}$

The empirical claim that is being made here is that non-iterable and/or nonsummative relations do not feed set formation. For instance, the linguistic fact that there can be at most one slobject that destroyed Rome might be expressed by saying that it is an element of the singleton set denoted by destroy Rome-but we will not do so. Instead, the denotation of a non-iterable predicate remains a slobject. The intuition behind this is that a predicate denotes a set only if it can in principle hold of more than one thing independently. Empirical support for this intuition comes from the data reviewed in Section 6.1 , i.e., the fact that the questioning of a unique parameter is sensitive to weak islands.

The definition of an answer to Who visited Rome? now involves (105), but that of an answer to Who destroyed Rome? can involve only (106):

(106) $\iota x\left[\operatorname{destroy}(\right.$ Rome $)(x)\left(f_{e}\right.$ (Rome) $\left.)\right]=$ ?

As regards Who didn't visit Rome?, Who visited every city?, and Who visited $a(n y)$ city? the reasoning in 6.1 can be reproduced as follows. If we have sets, as in (105), we can form their complements, or we can intersect and union them with others. The outputs also feed the Boolean operations.

(107) $-\left\{x: \exists e\left[e\right.\right.$ is the sum of minimal events $e_{m / i}$ of visiting Rome within some fixed event range $I \quad \& \quad x$ is the unique agent of some $\left.\left.e_{m / i} \subset e\right]\right\}=$ ?

(108) $\bigcap_{n \in N}\left\{x: \exists e\left[e\right.\right.$ is the sum of minimal events $e_{m / i}$ of visiting city ${ }_{n}$ within some fixed event range $I \quad \& \quad x$ is the unique agent of some $\left.\left.e_{m / i} \subset e\right]\right\}=$ ? 
(109) $\bigcup_{n \in N}\left\{x: \exists e\left[e\right.\right.$ is the sum of minimal events $e_{m / i}$ of visiting city ${ }_{n}$ within some fixed event range $I \& \quad x$ is the unique agent of some $\left.\left.e_{m / i} \subset e\right]\right\}=$ ?

But since destroy Rome does not denote a set, no complement can be formed, and Who didn't destroy Rome? is correctly predicted to be ungrammatical. ${ }^{24}$ Similarly, Who destroyed every city? cannot have a reading parallel to (108). The same sentence is grammatical on the family-of-questions reading (which does not concern us here) and on the reading which presupposes that the same agent (slobject) destroyed every city, cf. (42b). This latter will be expressed roughly as follows:

$$
\iota x \forall z\left[\operatorname{destroy}\left(\operatorname{city}_{z}\right)(x)\left(f_{e}\left(\operatorname{city}_{z}\right)\right)\right]=?
$$

It might be tempting to revise the set formation assumptions to allow for an alternative representation of this reading. The intersection of singletons is nonempty iff the singletons are identical:

$$
\bigcap_{i \in I}\left\{x:\left[\operatorname{destroy}\left(\operatorname{city}_{i}\right)(x)\left(f_{e}\left(\operatorname{city}_{i}\right)\right)\right]\right\}=?
$$

However, this interpretation asserts, rather than presupposes, that the same agent destroyed every city, which seems counterintuitive. Furthermore, it would predict that as a next step, a complement can be formed: Who didn't destroy every city? This is wrong, so (110) must be the correct representation.

The grammatical Who destroyed a(ny) city? may be puzzling: the destruction of each city is non-iterable, but that of an arbitrary city is iterable. Due to the first fact we cannot use (109). But we can capitalize on the fact that precisely in this case the event parameter is a function of the theme, whence they share an index:

(112) $\left\{x: \exists e\left[e\right.\right.$ is the sum of minimal events $e_{m / i}$ that are destructions of some city $_{i}$ within some fixed event range $I \quad \& \quad x$ is the unique agent of some $\left.\left.e_{m / i} \subseteq e\right]\right\}=$ ?

With these considerations in mind, we can turn to the classical cases of manners and amounts.

First, the slobject denoted by the manner parameter is typically a sum:

(113) behave $([$ kindly $\oplus$ stupidly $])([\mathrm{John}])\left(\left[e_{m / i}\right]\right)$

Second, while both the behaved kindly but stupidly and the John behaved relations are iterable, summativity fails (we never get cumulative readings):

\footnotetext{
${ }^{24}$ Alternatively, if Who didn't destroy Rome? is interpreted as ' $\iota x[\operatorname{destroy}(\mathrm{Rome})(x)] \neq ?$, , then an exhaustive answer like Hannibal leads to absurd consequences (e.g., Hannibal is the unique slobject not identical to Rome's destroyer, ergo every other slobject is identical).
} 
(114) John behaved kindly at event $e$ and John behaved stupidly at event $e^{\prime} \not \nrightarrow$ John behaved kindly and stupidly at $e \cup e^{\prime}$

(115) John behaved kindly at event $e$ and Bob behaved stupidly at event $e \not t$ John and Bob behaved kindly and stupidly at event $e$

As a consequence, set formation does not take place. How didn't you behave? and How did everyone behave? are both out on the wide scope how reading. The latter sentence has a family-of-questions reading and one analogous to (110).

Amounts may arise in two different ways, cf. John weighs ninety pounds and John visited two cities. Both require an additive measure: the value assigned to the sum of two non-overlapping slobjects $z$ and $z^{\prime}$ is the sum of the values assigned to $z$ and to $z^{\prime}$ (o stands for 'overlap'):

(116) The function $\mu$ is an additive measure iff

$$
\left(\neg\left(z \circ z^{\prime}\right) \wedge \mu(z)=n \wedge \mu\left(z^{\prime}\right)=n^{\prime}\right) \rightarrow \mu\left(z \cup z^{\prime}\right)=n+n^{\prime}
$$

For the sake of simplicity, we will only examine the two cities type. Following Krifka (1990), we take city to be the measure function. As long as the measured objects do not overlap, the summativity tests that failed above will work here, and we get cumulative readings:

(117) John visited six cities at $e$ and John visited five cities at $e^{\prime} \rightarrow$ John visited eleven cities at $e \cup e^{\prime}$

(118) John visited six cities at $e$ and Bob visited five cities at $e \rightarrow$ John and Bob visited eleven cities at $e$

These measures are not part of the characterization of the minimal event: measuring is an operation performed on sets or slobjects assembled on the basis of minimal events. In How many cities did John visit?, for instance, the set of cities that John visited is constructed and $\mu$ is applied to that set:

(119) $\mu\left(\left\{x: \exists e\left[e\right.\right.\right.$ is the sum of minimal events $e_{m / i}$ of John visiting a city within some fixed event range $I \quad \& \quad x$ is the unique theme of some $\left.\left.\left.e_{m / i} \subseteq e\right]\right\}\right)=$ ?

Similarly, a good reading can be constructed for How many cities didn't you visit?, etc. by measuring the complement of the set of cities visited: ${ }^{25}$

\footnotetext{
${ }^{25}$ This option is not available for *How many circles didn't John draw? if drawing is understood as creation, and John is not contrastive. This question is equivalent to ${ }^{*}$ How many circles aren't there?; there is no complement that could be formed. We suggest to capture this by measuring non-iterable events directly. The elaboration of this suggestion goes beyond the scope of this paper. (See Doetjes and Honcoop 1996 for related ideas, however.)
} 
(120) $\mu\left(-\left\{x: \exists e\left[e\right.\right.\right.$ is the sum of minimal events $e_{m / i}$ of John visiting a city within some fixed event range $I \quad \& \quad x$ is the unique theme of some $e m / i \subseteq e]\})=$ ?

For the cumulative reading of John and Bob visited eleven cities, the two sets of cities are unioned before measuring (we do not provide a general algorithm here):

(121) $\mu\left(\left\{x: \exists e\left[e\right.\right.\right.$ is the sum of minimal events $e_{m / i}$ of John visiting a city within some fixed event range $I \quad \& \quad x$ is the unique theme of some $\left.\left.e_{m / i} \subseteq e\right]\right\}$

$\mu\left\{x: \exists e\left[e\right.\right.$ is the sum of minimal events $e_{m / i}$ of John visiting a city within some fixed event range $I \quad \& \quad x$ is the unique theme of some $\left.\left.\left.e_{m / i} \subseteq e\right]\right\}\right)=$ ?

Measuring differs from the Boolean operations in two respects: its input does not have to be a set, and its output is certainly not a set. For the latter reason $\mu$ cannot be followed by the Boolean operations. How many cities didn't you visit? is ungrammatical on the reading that asks for the complement of the number of cities visited, and so on.

In other words, there are two reasons why Boolean operations may be unavailable: one is that we were never able to form sets in the first place, and the other is that our sets were subjected to an operation whose value is itself not a set.

\section{WEAK ISLANDS-SYNTAX OR SEMANTICS?*}

The traditional analysis of weak islands is purely syntactic: it relies on argument/adjunct asymmetries and escape hatches. Recent literature indicates that the generalizations holding for a wider natural class of weak islands have a semantic flavor: D-linking and intervening operators have been shown to play a role. Nevertheless, the theoretical terms in which Relativized Minimality is formulated are syntactic. In this paper we have argued that at least a significant subset of the data can be explained in semantic terms. It may be interesting to ask what the scope of the proposal is.

The present paper has made two independent claims. One is that many weak island violations are due to the failure of the $w h$-phrase to take scope over some intervening operator; see also Dobrovie-Sorin (1992), É. Kiss (1992), and de Swart (1992). Neither these works, nor the present paper has demonstrated, however, that all weak islands are scopal. The other claim, entirely

\footnotetext{
*This section originally contained tentative analyses of two further phenomena. These have been eliminated in the interest of brevity.
} 
our own, concerns the semantic explanation of one type of scopal failure. We have argued that a $w h$-phrase (or quantifier) can take scope over another scopal element SE only if the operations associated with SE are defined for its denotation domain. If the requisite operations are not defined, the intended reading is simply incoherent. We have offered an analysis in this spirit of a suggestive set of examples, many of which do not seem to have an independent syntactic account: consider the claim that different $w h$-phrases are sensitive to different weak islands, and the claim that arguments of non-iterable predicates are sensitive to weak islands.

If our semantic claim concerning scope-taking is logically correct, then it captures an absolute limitation on what meanings are expressible. It is not a matter of elegance whether one invokes it in the explanation of certain phenomena: it will be in effect even if the readings it excludes can be excluded in syntactic terms as well. In this sense it is truly not a rival of syntactic accounts. We expect that the syntactic and semantic explanations of weak island facts will eventually properly overlap. We expect many of the semantic constraints to have syntactic correlates: ones that have independent syntactic motivation, or ones that are semantically motivated but are compatible with independent syntactic considerations. There may remain important cases that are excluded only semantically or only syntactically. Dobrovie-Sorin's (1992) and Beghelli's (1993) work appears to point to this conclusion.

\section{REFERENCES}

Aoun, Joseph. 1986. Generalized Binding. Dordrecht: Foris.

Barwise, Jon. 1979. On branching quantifiers in English. Journal of Philosophical Logic 8(1):47-80.

Beghelli, Filippo. 1993. A minimalist approach to quantifier scope. In Amy J. Schafer (Ed.), Proceedings of the North East Linguistic Society 23, Volume One, 65-80, Amherst. GLSA Publications, University of Massachussetts.

Carlson, Gregory. 1984. Thematic roles and their role in semantic interpretation. Linguistics 22(3):259-279.

Cattell, Ray. 1978. On the source of interrogative adverbs. Language 54(1):6177.

Chierchia, Gennaro. 1984. Topics in the Syntax and Semantics of Infinitives and Gerunds. PhD thesis, University of Massachussetts, Amherst. 
Chierchia, Gennaro. 1992. Functional WH and weak crossover. In Dawn Bates (Ed.), The Proceedings of the Tenth West Coast Conference on Formal Linguistics, 75-90, Stanford. CSLI.

Chung, Sandra. 1992. Wh-agreement and 'referentiality' in chamorro. Unpublished manuscript, UCSC.

Cinque, Guglielmo. 1990. Types of $A^{\prime}$-Dependencies. Cambridge: MIT Press.

Comorovski, Ileana. 1989. Discourse and the Syntax of Multiple Constituent Questions. PhD thesis, Cornell University.

Dobrovie-Sorin, Carmen. 1992. LF representations, weak islands, and the ECP. GLOW Newsletter 27:14-15.

Doetjes, Jenny, and Martin Honcoop. 1996. On event-relatedness, symmetry and weak islands. In this volume.

Dukes, Michael. 1992. Factives, 'stance' predicates, and weak islandhood. Unpublished manuscript, UCLA.

Enç, Mürvet. 1991. The semantics of specificity. Linguistic Inquiry 22(1):1-25.

Engdahl, Elisabet. 1985. Constituent Questions. Dordrecht: Reidel.

Frampton, John. 1990. The fine structure of WH movement and the proper formulation of the ECP. Unpublished manuscript.

Groenendijk, Jeroen, and Martin Stokhof. 1984. Studies on the Semantics of Questions and the Pragmatics of Answers. PhD thesis, University of Amsterdam.

Gutiérrez Rexach, Javier. 1996. Questions and generalized quantifiers. In this volume.

Harada, Yasunari, and Naohiko Noguchi. 1992. On the semantics and pragmatics of dake (and only). In Chris Barker and David Dowty (Eds.), SALT II: Proceedings of the Second Conference on Semantics and Linguistic Theory (OSU WPL 40), 125-145, Columbus. The Ohio State University.

Hegarty, Michael. 1992. Adjunct extraction without traces. In Dawn Bates (Ed.), The Proceedings of the Tenth West Coast Conference on Formal Linguistics, 209-222, Stanford. CSLI.

Hepple, Mark. 1990. The Grammar and Processing of Order and Dependency: A Categorial Approach. PhD thesis, Edinburgh University. 
Higginbotham, James. 1991. Interrogatives I. In Lisa Cheng and Hamida Demirdash (Eds.), More Papers on WH-Movement (MIT WPL 15), 47-76, Cambridge. MIT.

Keenan, Edward, and Leonard Faltz. 1985. Boolean Semantics for Natural Language. Dordrecht: Reidel.

Keenan, Edward, and Alan Timberlake. 1988. Natural language motivation for extending categorial grammar. In Richard Oehrle et al. (Eds.), Categorial Grammars and Natural Language Structures, 265-296. Dordrecht: Kluwer.

Kiss, Tibor. 1991. Some properties of negation in German. Stuttgart, Unpublished manuscript.

É. Kiss, Katalin. 1991. Logical structure in linguistic structure: The case of Hungarian. In James Huang and Robert May (Eds.), Logical Structure and Linguistic Structure, 387-426. Dordrecht: Kluwer.

É. Kiss, Katalin. 1992. Wh-movement and specificity. Natural Language and Linguistic Theory 11(1):85-120.

Krifka, Manfred. 1990. Four thousand ships passed through the lock. Linguistics and Philosophy 13(5):487-520.

Kroch, Anthony. 1989. Amount quantification, referentiality and long WHmovement. Unpublished manuscript.

Ladusaw, William. 1980. Affective OR, factive verbs, and negative polarity items. In Jody Kreiman and Almerindo Ojeda (Eds.), Papers from the Sixteenth Regional Meeting: Chicago Linguistics Society, 170-184.

Landman, Fred. 1986. Towards a Theory of Information. Dordrecht: Foris.

Landman, Fred. 1991. Structures for Semantics. Dordrecht: Kluwer.

Liu, Feng-hsi. 1990. Scope Dependency in English and Chinese. PhD thesis, UCLA.

Liu, Feng-hsi. 1992. Branching quantification and scope independence. In Jaap van der Does and Jan van Eijck (Eds.), Generalized Quantifier Theory and Applications, 297-331. Chicago: CSLI/University of Chicago Press.

May, Robert. 1985. Logical Form: Its Structure and Derivation. Cambridge: MIT Press. 
Melvold, Janis. 1991. Factivity and definiteness. In Lisa Cheng and Hamida Demirdash (Eds.), More Papers on WH-Movement (MIT WPL 15), 97-117. Cambridge: MIT.

Molnár, Ilona. 1982. Existential relations in hogy 'that'-sentences. In Ferenc Kiefer (Ed.), Hungarian Linguistics, 111-147. Amsterdam: John Benjamins.

Moltmann, Friederike. 1994. Attitude reports, events and partial models. Unpublished manuscript.

Pesetsky, David. 1987. Wh-in-situ: Movement and unselective binding. In Eric Reuland and Alice ter Meulen (Eds.), The Representation of (In) definiteness, 98-130. Cambridge: MIT Press.

Philip, William, and Jill de Villiers. 1992. Monotonicity and the acquisition of weak islands. Talk Presented at the Stanford Conference on Child Language.

Progovac, Ljiljana. 1988. A Binding Approach to Polarity Sensitivity. PhD thesis, University of Southern California.

Rizzi, Luigi. 1990. Relativized Minimality. Cambridge: MIT Press.

Rizzi, Luigi. 1992. Argument/adjunct (a)symmetries. In NELS 22: Proceedings of the North East Linguistic Society, 365-381. GLSA Publications, University of Massachussetts, Amherst.

Sántha, Miklós. 1980. Some problems of the semantic treatment of thatclauses in Montague Grammar. Computational Linguistics and Computer Languages 14(1):67-79.

Scha, Remko. 1981. Distributive, collective, and cumulative quantification. In Jeroen Groenendijk et al. (Eds.), Formal Methods in the Study of Language, 483-512. Amsterdam: Mathematisch Centrum.

Schein, Barry. 1993. Plurals and Events. Cambridge: MIT Press.

Sher, Gila. 1991. The Bounds of Logic. A Generalized Viewpoint. Cambridge: MIT Press.

Steedman, Mark. 1987. Combinatory Grammar and parasitic gaps. Natural Language and Linguistic Theory 5(3):403-440.

de Swart, Henriëtte. 1992. Intervention effects, monotonicity and scope. In Chris Barker and David Dowty (Eds.), SALT II: Proceedings of the Second Conference on Semantics and Linguistic Theory (OSU WPL 40), 387-406, Columbus. The Ohio State University. 
Szabolcsi, Anna. 1983. Focussing properties, or the trap of first order. Theoretical Linguistics 10(2/3):125-145.

Szabolcsi, Anna. 1986. From the definiteness effect to lexical integrity. In Werner Abraham and Sjaak de Meij (Eds.), Topic, Focus and Configurationality, 321-348. Amsterdam: John Benjamins.

Szabolcsi, Anna. 1991. Islands, monotonicity, composition, and heads. GLOW Newsletter 26:58-59.

Szabolcsi, Anna. 1992a. Combinatory Grammar and projection from the lexicon. In Ivan Sag and Anna Szabolcsi (Eds.), Lexical Matters, 241-268. Stanford: CSLI.

Szabolcsi, Anna. 1992b. Weak islands, individuals, and scope. In Chris Barker and David Dowty (Eds.), SALT II: Proceedings of the Second Conference on Semantics and Linguistic Theory (OSU WPL 40), 407-438, Columbus. The Ohio State University.

Szabolcsi, Anna. 1996. Quantifiers in pair-list readings. In this volume.

Szabolcsi, Anna, and Frans Zwarts. 1990. Semantic properties of composed functions and the distribution of Wh-phrases. In Proceedings of the Seventh Amsterdam Colloquium, 529-555. Amsterdam: Institute for Language, Logic, and Information.

Szabolcsi, Anna, and Frans Zwarts. 1991. Unbounded dependencies and algebraic semantics. Lecture Notes from the 3rd European Summer School in Language, Logic and Information.

Szabolcsi, Anna, and Frans Zwarts. 1993. Weak islands and an algebraic semantics of scope taking. Natural Language Semantics 1(3):235-284. Reprinted in this volume.

Westerståhl, Dag. 1985. Logical constants in quantifier languages. Linguistics and Philosophy 8(4):387-413.

Williams, Edwin. 1974. Rule Ordering in Syntax. PhD thesis, MIT.

Zimmermann, Ede. 1991. Scopeless quantifiers and operators. In Jaap van der Does and Jan van Eijck (Eds.), Generalized Quantifier Theory and Applications, 207-223. Amsterdam: Dutch Network for Language, Logic and Information.

Zwarts, Frans. 1986. Categoriale Grammatika en Algebraïsche Semantiek. PhD thesis, University of Groningen. 